\title{
A new method for evaluating the impact of vertical distribution on aerosol radiative forcing in general circulation models
}

\author{
M. R. Vuolo ${ }^{1, *}$, M. Schulz ${ }^{2,1}$, Y. Balkanski ${ }^{1}$, and T. Takemura ${ }^{3}$ \\ ${ }^{1}$ Laboratoire des Sciences du Climat et l'Environnement, UMR8212, CEA-CNRS-UVSQ, Gif-sur-Yvette, France \\ ${ }^{2}$ Norwegian Meteorological Institute, Oslo, Norway \\ ${ }^{3}$ Research Institute for Applied Mechanics, Kyushu University, 6-1 Kasuga-koen, Kasuga, Fukuoka 816-8580, Japan \\ *now at: Institut National de la Recherche Agronomique, Thiverval-Grignon, France
}

Correspondence to: M. R. Vuolo (mrvuolo@gmail.com)

Received: 17 May 2013 - Published in Atmos. Chem. Phys. Discuss.: 15 July 2013

Revised: 21 November 2013 - Accepted: 5 December 2013 - Published: 24 January 2014

\begin{abstract}
The quantification and understanding of direct aerosol forcing is essential in the study of climate. One of the main issues that makes its quantification difficult is the lack of a complete understanding of the role of the vertical distribution of aerosols and clouds. This work aims at reducing the uncertainty of aerosol top-of-the-atmosphere (TOA) forcing due to the vertical superposition of several short-lived atmospheric components, in particular different aerosol species and clouds. We propose a method to quantify the contribution of different parts of the atmospheric column to the TOA forcing as well as to evaluate the contribution to model differences that is exclusively due to different spatial distributions of aerosols and clouds. We investigate the contribution of aerosol above, below and in clouds by using added diagnostics in the aerosol-climate model LMDz. We also compute the difference between the TOA forcing of the ensemble of the aerosols and the sum of the forcings from individual species in clear sky. This difference is found to be moderate for the global average (14\%) but can reach high values regionally (up to $100 \%$ ). Nonlinear effects are even more important when superposing aerosols and clouds. Four forcing computations are performed: one where the full aerosol 3-D distribution is used, and then three where aerosols are confined to regions above, inside and below clouds, respectively. We find that the TOA forcing of aerosols depends crucially on the presence of clouds and on their position relative to that of the aerosol, in particular for black carbon (BC). We observe a strong enhancement of the TOA forcing of BC above clouds, attenuation for $\mathrm{BC}$ below clouds, and a moderate enhancement when $\mathrm{BC}$ is found within clouds. $\mathrm{BC}$ above
\end{abstract}

clouds accounts for only about $30 \%$ of the total BC optical depth but for $55 \%$ of the forcing, while forcing efficiency increases by a factor of 7.5 when passing from below to above clouds.

The different behaviour of forcing nonlinearities for these three components of the atmospheric column encouraged us to develop the method for application to inter-model variability studies by reading 3-D aerosol and cloud fields from different general circulation models (GCMs) into the same model. We apply the method to the comparison of forcing due to the aerosols and clouds distributions of the general circulation models LMDz and SPRINTARS. The different amount of BC above but also within clouds is revealed to play a major role on the differences of cloudy-sky forcings between the two models, which can exceed $100 \%$ regionally.

\section{Introduction}

Quantifying the effect of the vertical overlapping of atmospheric components on the radiative fluxes is not a straightforward problem. Indeed, TOA forcing is nonlinear with respect to the aerosol amount (Charlson et al., 1992), although Boucher et al. (1998) suggested a small nonlinearity for a range of global sulfate burdens corresponding to $0.1-$ 0.5 AOD (aerosol optical depth). From a modelling point of view, it is necessary to deal with multiple scattering among layers (nonlinear processes) and the strong dependency on the scattering and absorbing characteristics of the superposed layers (Meloni et al., 2005; Gómez-Amo et al., 2010). From 
an experimental point of view, the technology of active remote sensing, which allows for vertically resolved study of the atmospheric components, is relatively recent and does not provide information behind optically thick objects, e.g. below clouds viewed from space (Chepfer et al., 2008; Vuolo et al., 2009; Koffi et al., 2012). Concerning the coexistence of different aerosols within the same atmospheric column, many works have assumed that for externally mixed aerosols, the effects of individual aerosol species add linearly to constitute the total TOA forcing (Podgorny and Ramanathan, 2001; Boucher and Haywood, 2001; Reddy et al., 2005). The effect of clouds below absorbing aerosols has been studied since the late 1990s by means of column radiative models (Haywood and Shine, 1997; Liao and Seinfeld, 1998; Zarzycki and Bond, 2010) and general circulation models (e.g. Haywood Ramaswamy, 1998), and, more recently, using satellite data (Chand et al., 2008; Peters et al., 2011), but the aerosol TOA forcing in all sky and cloudy-sky conditions remains highly uncertain (Schulz et al., 2006; Myhre et al., 2013). Some studies on radiative forcing used or had to use (when based on satellite data) the assumption that aerosol effects are negligible in cloudy regions as they are "masked" by clouds (Bellouin et al., 2005). This was shown to be an important source of discrepancy between observation- and model-based forcing estimates (Bellouin et al., 2008).

A single-column model has the advantage that one may isolate a single physical effect; however, it requires many assumptions to demonstrate the importance of the effect for the real atmosphere. General circulation models (GCMs) or chemistry transport models (CTMs) are more suitable for estimating the impact of a phenomenon on the global scale. Haywood and Ramaswamy (1998) studied the dependency of TOA forcing on the vertical position of aerosols, as well as the effect of clouds, by concentrating all the aerosol content in only one model level, from the surface to $25 \mathrm{~km}$. They found that black carbon (BC) forcing for the same BC burden varies with increasing altitude from 0.45 to $0.9 \mathrm{~W} \mathrm{~m}^{-2}$. More recently, $\mathrm{BC}$ direct forcing divided by the burden, computed as a function of altitude in a 3-D CTM, is reported to increase considerably with height (Samset and Myhre, 2011), ranging from $380 \mathrm{~W} \mathrm{~g}^{-1}$ at $1000 \mathrm{hPa}$ to $3800 \mathrm{~W} \mathrm{~g}^{-1}$ at $20 \mathrm{hPa}$. The dependency of the $\mathrm{BC}$ radiative forcing from the vertical profile has been estimated to be responsible for 20 to $50 \%$ of the spread in forcing values of AeroCom models by use of a common forcing efficiency vertical profile (Samset et al., 2013). This sensitivity of forcing to vertical distribution is expected to be responsible for an important part of the actual inter-model forcing differences. A comparison of aerosol vertical distributions with respect to CALIOP observations (Koffi et al., 2012) shows a large spread in the distribution simulated by GCMs.

This study aims to quantify, in more detail, the sensitivity of TOA forcing to vertical position of aerosols through the use of realistic aerosol and cloud distributions as well as by focusing on the relative position of distinct aerosol and cloud layers. It documents the importance of the vertical superposition of aerosol (primarily black carbon) with clouds and the superposition of distinct aerosol layers at the global scale. We analyse the role of the relative vertical position of several atmospheric agents by quantifying the nonlinearity of forcing, i.e. the difference between the actual forcing and the sum of the forcings of the individual components. This is done for different combinations of aerosol and cloud layers, which are realized in our specific model setup, where we identify aerosols above, below and in clouds in the cloudy area. These nonlinearities allow us to quantify (1) the amount of the error when considering the total forcing as the sum of the forcings of the individual components, and (2) the importance of a correct representation of the "vertical layering" (that is, which aerosol component is below and which one is above). We will show that, for the same aerosol optical thickness of an aerosol component, its position relative to that of other species and clouds has a large impact on the resulting TOA forcing. As the cloudy- and all-sky forcing is highly variable among GCMs (Schulz et al., 2006; Myhre et al., 2013), we finally illustrate the impact of the vertical position of $\mathrm{BC}$ and clouds on this variability by introducing the 3-D fields of aerosols and clouds from two different models in the same host model and then computing forcing differences. In this way, the spatial distribution of aerosols and clouds affect the forcing differences, while other factors like surface albedo, aerosol optical properties, meteorological and radiative computations have no impact because they are computed by the same host model.

\section{Atmospheric TOA forcing due to the position of cloud and aerosol layers}

The radiative forcing according to Intergovernmental Panel on Climate Change (IPCC) is the change in net radiative flux at the tropopause due to an atmospheric agent after allowing for stratospheric temperatures to readjust to radiative equilibrium, but with surface and tropospheric temperatures and state held fixed at the unperturbed values (IPCC, 2007). Radiative forcing values are typically presented with respect to a pre-industrial reference, but the definition of forcing we adopt here considers a state with no aerosols instead of preindustrial aerosols as reference and uses TOA flux changes. In IPCC terms it would be called a radiative effect. Our approach simplified the experiments and allowed for dust and sea salt radiative effects to be studied also.

We consider only the shortwave contribution to the aerosol TOA forcing, as the longwave forcing is a negligible part of the direct aerosol forcing except for dust and, to a smaller extent, for sea salt (Reddy et al., 2005). If interactions occur between the added atmospheric agent and the environment, the forcing will depend on the environment (for instance, a cloudy environment for aerosols). In the same way, if two atmospheric agents (for example, aerosols and clouds or two 

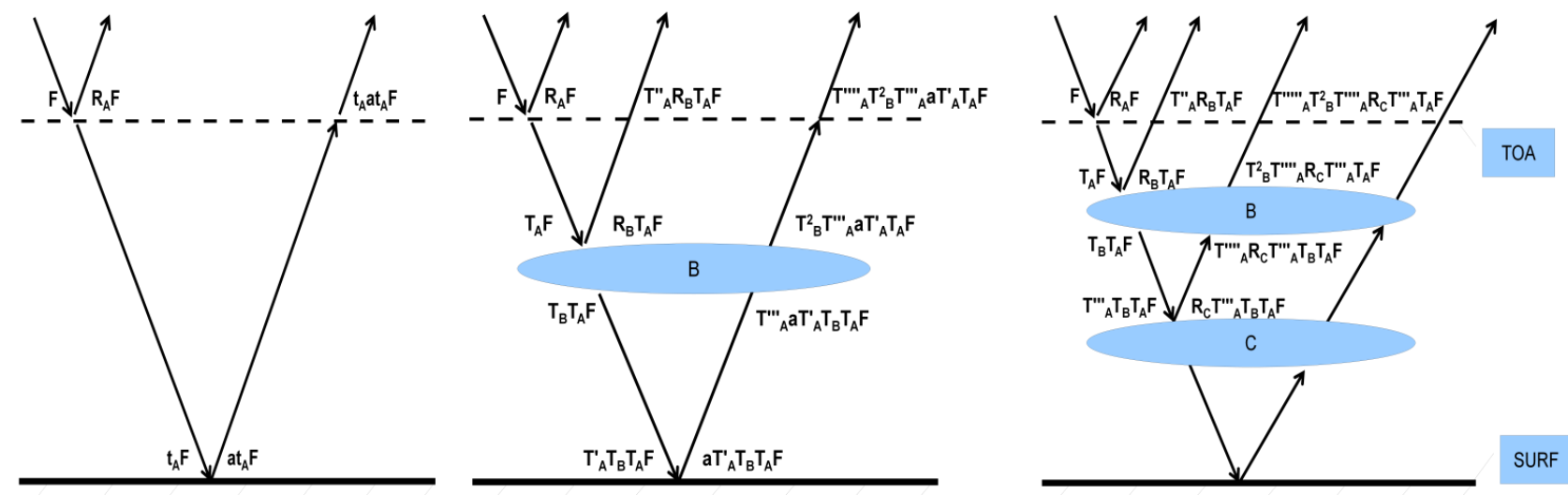

Fig. 1. Diagram of the computation of net fluxes at the top of the atmosphere (TOA) for completely clear sky (left) in the presence of an atmospheric agent " $B$ " (centre) and in presence of two superposed atmospheric agents " $B$ " and " $C$ " (right). For ease of reading, at each interaction between the flux and an atmospheric agent, we indicate as the first factor the coefficient that describes the last modification of the flux. Here, $t$ and $\mathrm{T}$ transmissivities for clear sky and with the presence of an atmospheric agent, respectively; $R$ is the reflectivity; and $a$ is the surface albedo. For a given atmospheric layer, $T+R+A=1$ ( $A=$ absorptivity). Transmissivity is related to the optical depth $\tau$ by the relation $T=\exp (-\tau)$.

distinct aerosol species) interact amongst themselves, the total forcing will be different from the sum of the forcings from the individual components.

Indeed, we can easily show that the two effects are physically equivalent according to the definition of TOA forcing. Here, we use $F(B)$ as the net TOA flux that incorporates only the atmospheric agent " $B$ " (e.g. black carbon), and $\operatorname{RF}(B)$ as the radiative TOA forcing from " $B$ ". With $\mathrm{dRF}$ as the difference between the forcing of agent " $B$ " in an environment where " $C$ " (e.g. clouds) is present $(\operatorname{RF}(B \mid C))$ minus the forcing of " $B$ " alone $(\operatorname{RF}(B))$, we have

$\mathrm{dRF}=\operatorname{RF}(B \mid C)-\operatorname{RF}(B)$.

Since $\operatorname{RF}(B \mid C)=F(B+C)-F(C)$, we can rewrite Eq. (1) in the following way:

$$
\begin{aligned}
\mathrm{dRF} & =[F(B+C)-F(\text { clear })]-[F(C)-F(\text { clear })]-\mathrm{RF}(B) \\
& =\mathrm{RF}(B+C)-\mathrm{RF}(B)-\mathrm{RF}(C),
\end{aligned}
$$

where we added and subtracted $F$ (clear) to express the coupling term dRF in terms of the total forcing and the singlecomponent forcings. The difference $\mathrm{dRF}$ corresponds to the nonlinearity of combining forcings (or the coupling term). It is of interest for both the "cloudy-sky aerosol forcing" where the radiative interaction between clouds and aerosols gives rise to an important extra forcing term, in the form of Eq. (1) - and for the superposition of different aerosol components, where the nonlinearity arises in the form of Eq. (2). See Appendix A and Fig. 1 for more details.

The interaction between atmospheric agents (aerosols and clouds) can be of several kinds. The potential of aerosols to modify clouds optical properties is referred to as the first indirect effect (e.g. Twomey, 1991). Aerosols can also modify cloud microphysics through the second indirect effect (e.g. Albrecht, 1989). Moreover, absorbing aerosols can alter the atmospheric temperature profile, which impacts convection and cloud formation (the semi-direct effect; e.g. Hansen et al., 1997). Another kind of interaction is the one that occurs because of the exchange of radiation between two superposed layers of aerosols and clouds. In the framework of this study, only the last mentioned form of interaction is investigated. To achieve this objective, we eliminate semi-direct and indirect effects to better understand the effect of the exchanges of radiation between superposed layers (Sect. 3.4.3 below explains how this is done within the framework of this study).

\section{Method}

\subsection{LMDz host model and aerosol optical parameters}

The model used in our experiments is the general circulation model LMDz (Hourdin et al., 2006), with $95 \times 96$ horizontal resolution and 19 vertical levels. Meteorology is nudged with ECMWF reanalysis winds (Simmons et al., 2006) and HADiSST sea surface temperatures (Rayner et al., 2003). Aerosol fields are read as input into the model from monthly averages. In the reference experiment (see Sect. 2.4) these aerosols fields correspond to the year 2006 and are from a version of the LMDz-INCA model used for the recent forcing study in AeroCom Phase II (Myhre et al., 2013). The aerosol concentration at each time step is computed in LMDz by linear interpolation of the monthly mean values. The model accounts for the following four basic properties that influence optical parameters of the ambient aerosol: size, 
chemical composition, hygroscopicity and mixing state of the particles.

The size of the aerosol is represented in LMDz by a superposition of log-normal distributions. In this work, we treat sulfate, $\mathrm{BC}$ and organic carbon (OC) as external mixtures. Submicron aerosols are transported in two distinct modes: one that is soluble and another that is insoluble. We keep track of both soluble and insoluble BC and POM. We assume that primary, insoluble carbonaceous particles become soluble with time. The half-life of ageing for BC and POM is taken as 1.1 days based upon the study of Cooke and Wilson (1996). A ratio POM: $O C=1.4: 1$ was used. This value corresponds to the low range of the values reported in Turpin et al. (2001).

The uptake and loss of water to aerosol particles (hygroscopicity) is generally fast and depends on the chemical composition, size and surface properties of the aerosol particle. Hygroscopic growth (HG) of aerosol particles is a major factor that determines the optical parameters of an aerosol population. The model takes into account the observation that two types of particles with different HG factors appear upon hydration of dry particles of a given diameter. This is represented by the two modes: a soluble one and an insoluble one. HG changes the particle diameter, aerosol composition and particle surface characteristics. Typical wet diameters for each mode had already been precalculated in another LMDzINCA model run and used for computation and tabulation of optical parameters as a function of mode, species and relative humidity. The optical properties of the individual components are computed with this look-up table using the ambient relative humidity in the model grid cell. The overall optical properties of the global aerosol are then computed by summing the different contributions of the aerosol components to the extinction. For the single-scattering albedo, the different contributions are weighted with the respective specific extinction coefficients, and for the asymmetry parameter this is done by the product of the specific extinction and the single-scattering albedo.

\subsection{Radiative computations in $\mathrm{LMDz}$}

The shortwave radiative fluxes in the model LMDz are computed with the scheme developed in Fouquart and Bonnel (1980), fluxes in clear-sky and all-sky conditions are computed separately. The reflectivity and transmissivity of a grid cell column - being partly cloudy and thus reflecting "all-sky" conditions - are computed using the random cloud overlap assumption (Morcrette and Fouquart, 1986). All- and clear-sky fluxes are computed by separate calls to the radiation routine, either including or not including clouds radiative effects in the computations. This allows for separate computation of clear- and all-sky aerosol forcings. The shortwave spectrum is divided into two spectral intervals: 0.25$0.68 \mu \mathrm{m}$ and $0.68-4.00 \mu \mathrm{m}$. The radiation scheme is the one introduced by J. J. Morcrette in the model of the European
Centre for Medium-Range Weather Forecasts (ECMWF); for further details, we refer the reader to the online documentation of the ECMWF research department, available at http: //www.ecmwf.int/research/ifsdocs/pdf_files/Physics.pdf.

The aerosols direct and indirect effects have been introduced by Quaas et al. (2004), following Boucher and Pham (2002). In the default LMDz parametrization of the radiative effects of aerosols and clouds, direct and indirect effects (when activated) are taken into account in both forcing and meteorological fields computations. The fluxes that incorporate aerosol and clouds effects are used to influence the radiative-convective equilibrium of the atmospheric column. This explains why different aerosol and cloud fields in LMDz may give rise to different meteorological fields if such an effect is permitted by experiment setup. This is avoided in our experiments.

\subsection{Diagnosis of TOA forcings and forcing efficiencies}

In this study, we use a completely aerosol-free atmosphere as reference, as has been done in previous studies (Satheesh et al., 1999; Podgorny and Ramanathan, 2001; Takemura et al., 2002 and Reddy et al., 2005). This reference assures that there will be no dependency on the definition, spatial distribution and optical properties of pre-industrial aerosols, as this also is subject to uncertainties and can be different from one model to another (Visser et al., 2000). Thus, the direct radiative TOA forcings are computed as the difference between the net TOA flux with and without aerosols, both in clear- and cloudy-sky conditions $\left(\mathrm{RF}_{\mathrm{CS}}, \mathrm{RF}_{\mathrm{CL}}\right)$, for each species separately $\left(\mathrm{BC}, \mathrm{SO}_{4}, \mathrm{POM}, \mathrm{DUST}, \mathrm{SS}\right)$ and for the ensemble of all the species "AER".

Cloudy-sky radiative forcing, $\mathrm{RF}_{\mathrm{CL}}$, is calculated at each time step, and for each model cell, as

$\mathrm{RF}_{\mathrm{CL}}=\mathrm{RF}_{\mathrm{AS}}-(1-\mathrm{CLT}) \cdot \mathrm{RF}_{\mathrm{CS}}$,

where CLT is the cloudy fraction in each grid cell. This is similar to the cloudy-sky forcing definition as used by Schulz et al. (2006), but differs in that it is computed at every time step and when averaged it is not weighted by the cloud fraction. It is thus similar in concept to the clear-sky forcing definition. By using calculations for all time steps, we believe that we obtain a more reproducible forcing number. In Schulz et al. (2006), cloudy-sky forcing was computed only from annual fields of forcings and cloud fraction.

We compute clear- and cloudy-sky forcing efficiencies and relate them to the vertical positions (see below). The characteristic height of aerosols and clouds is computed by weighting their vertical coordinate with their optical thickness. The clear-sky forcing efficiency per unit aerosol optical depth $\mathrm{NRF}_{\mathrm{CS}}$ is computed as $\mathrm{RF}_{\mathrm{CS}} / \mathrm{AOD}$, with $\mathrm{RF}_{\mathrm{CS}}$ and AOD being yearly average values of clear-sky TOA forcing and optical depth. Analogously, the cloudy-sky forcing efficiency is computed as the ratio of the global averages of $\mathrm{RF}_{\mathrm{CL}}$ and AOD. We avoid computing efficiency with instantaneous 2-D 
Table 1. Model simulations according to the different origin of aerosols and clouds fields (Configurations) and aerosols vertical distributions relative to clouds (Experiments). "AER" stands for "aerosols" and "ccc" stands for "completely clear columns".

\begin{tabular}{|c|c|c|c|c|c|}
\hline Experiments & Full 3-D & $\mathrm{ABI}$ & $\mathrm{ABV}$ & IN & BLW \\
\hline \multicolumn{6}{|l|}{ Configurations } \\
\hline Default & $\begin{array}{l}\text { AER \& clouds } \\
\text { computed in } \\
\text { LMDz; full } \\
\text { 3-D aerosol } \\
\text { distribution }\end{array}$ & $\begin{array}{l}\text { AER \& clouds } \\
\text { computed in } \\
\text { LMDz; AOD =0 } \\
\text { in ccc }\end{array}$ & $\begin{array}{l}\text { AER \& clouds } \\
\text { computed in } \\
\text { LMDz; AOD } \neq 0 \\
\text { only above clouds }\end{array}$ & $\begin{array}{l}\text { AER \& clouds } \\
\text { computed in } \\
\text { LMDz; AOD } \neq 0 \\
\text { only inside clouds }\end{array}$ & $\begin{array}{l}\text { AER \& clouds } \\
\text { computed in } \\
\text { LMDz; AOD } \neq 0 \\
\text { only below clouds }\end{array}$ \\
\hline Reading LMDz & $\begin{array}{l}\text { Not } \\
\text { performed }\end{array}$ & $\begin{array}{l}\text { AER \& clouds } \\
\text { read from LMDz } \\
\text { previous results; } \\
\text { AOD }=0 \text { in ccc }\end{array}$ & $\begin{array}{l}\text { AER \& clouds } \\
\text { read from } \mathrm{LMDz} \\
\text { previous results; } \\
\text { AOD } \neq 0 \text { only } \\
\text { above clouds }\end{array}$ & $\begin{array}{l}\text { AER \& clouds } \\
\text { read from LMDz } \\
\text { previous results; } \\
\text { AOD } \neq 0 \text { only } \\
\text { inside clouds }\end{array}$ & $\begin{array}{l}\text { AER \& clouds } \\
\text { read from LMDz } \\
\text { previous results; } \\
\text { AOD } \neq 0 \text { only } \\
\text { below clouds }\end{array}$ \\
\hline Reading SPRINTARS & $\begin{array}{l}\text { Not } \\
\text { performed }\end{array}$ & $\begin{array}{l}\text { AER \& clouds } \\
\text { read from } \\
\text { SPRINTARS } \\
\text { previous results; } \\
\text { AOD }=0 \text { in ccc }\end{array}$ & $\begin{array}{l}\text { AER \& clouds } \\
\text { read from } \\
\text { SPRINTARS } \\
\text { previous results; } \\
\text { AOD } \neq 0 \text { only } \\
\text { above clouds }\end{array}$ & $\begin{array}{l}\text { AER \& clouds } \\
\text { read from } \\
\text { SPRINTARS } \\
\text { previous results; } \\
\text { AOD } \neq 0 \text { only } \\
\text { inside clouds }\end{array}$ & $\begin{array}{l}\text { AER \& clouds } \\
\text { read from } \\
\text { SPRINTARS } \\
\text { previous results; } \\
\text { AOD } \neq 0 \text { only } \\
\text { below clouds }\end{array}$ \\
\hline $\begin{array}{l}\text { Reading LMDz aerosols } \\
\text { - SPRINTARS clouds }\end{array}$ & $\begin{array}{l}\text { Not } \\
\text { performed }\end{array}$ & $\begin{array}{l}\text { AER (clouds) } \\
\text { read from LMDz } \\
\text { (SPRINTARS) } \\
\text { previous results; } \\
\text { AOD }=0 \text { in ccc }\end{array}$ & $\begin{array}{l}\text { AER (clouds) } \\
\text { read from LMDz } \\
\text { (SPRINTARS) } \\
\text { previous results; } \\
\text { AOD } \neq 0 \text { only } \\
\text { above clouds }\end{array}$ & $\begin{array}{l}\text { AER (clouds) } \\
\text { read from LMDz } \\
\text { (SPRINTARS) } \\
\text { previous results; } \\
\text { AOD } \neq 0 \text { only } \\
\text { inside clouds }\end{array}$ & $\begin{array}{l}\text { AER (clouds) } \\
\text { read from LMDz } \\
\text { (SPRINTARS) } \\
\text { previous results; } \\
\text { AOD } \neq 0 \text { only } \\
\text { below clouds }\end{array}$ \\
\hline $\begin{array}{l}\text { Reading SPRINTARS } \\
\text { aerosols - LMDz clouds }\end{array}$ & $\begin{array}{l}\text { Not } \\
\text { performed }\end{array}$ & $\begin{array}{l}\text { AER (clouds) } \\
\text { read from } \\
\text { SPRINTARS } \\
\text { (LMDz) } \\
\text { previous results; } \\
\text { AOD }=0 \text { in ccc }\end{array}$ & $\begin{array}{l}\text { AER (clouds) } \\
\text { read from } \\
\text { SPRINTARS } \\
\text { (LMDz) } \\
\text { previous results; } \\
\text { AOD } \neq 0 \text { only } \\
\text { above clouds }\end{array}$ & $\begin{array}{l}\text { AER (clouds) } \\
\text { read from } \\
\text { SPRINTARS } \\
\text { (LMDz) } \\
\text { previous results; } \\
\text { AOD } \neq 0 \text { only } \\
\text { inside clouds }\end{array}$ & $\begin{array}{l}\text { AER (clouds) } \\
\text { read from } \\
\text { SPRINTARS } \\
\text { (LMDz) } \\
\text { previous results; } \\
\text { AOD } \neq 0 \text { only } \\
\text { below clouds }\end{array}$ \\
\hline
\end{tabular}

fields of forcing and optical depth because it requires the choice of a threshold for the optical depth to avoid numerically occurring, but unrealistically high, values of efficiency when AOD is very low. Furthermore, such a choice cannot be the same for each aerosol species, which would require different threshold values of optical depth.

\subsection{Model simulations}

In the following we will present a method that we have developed to study the dependency of TOA forcing on the vertical distribution of aerosols and clouds. Two questions are addressed: what is the contribution to the forcing from aerosols below, inside and above clouds, and what is the potential difference between two model results introduced by different vertical distributions of aerosols and clouds? The method requires multiple model runs where the radiative TOA forcing due to specific portions of the aerosol burden is computed.
For example, to compute the forcing from aerosol above clouds, aerosol optical depth above clouds is kept the same as in the reference run, while aerosol optical depth in and below clouds is set to zero. These runs are classified below in terms of model configurations and experiments. Aerosol and cloud fields are either computed interactively or read from previously realized atmospheric chemistry simulations, performed with the host model LMDz and with the model SPRINTARS (Takemura et al., 2005). Other host model factors like resolution, solar fluxes, surface albedo, intensive aerosol optical properties, etc., are invariable between the runs.

To quantify the amount of inter-model forcing differences that can be attributed to different vertical distributions of aerosols and clouds, we run the model LMDz in five different configurations, while to attribute the forcing to aerosols below, inside and above clouds, we perform four different experiments for each configuration (see Table 1). 


\subsubsection{The configurations}

The five configurations differ in the origin of the aerosol and eventually cloud fields that are read into the model LMDz. They are defined as follows:

1. The "default" configuration: monthly fields of aerosols from a previous model run are read as input, and cloud fields are computed interactively at each time step.

2. The "reading LMDz" configuration: the same monthly aerosols as in configuration 1 are read, but daily cloud fields from the default configuration are also read and are used in the radiation code.

3. The "reading SPRINTARS" configuration: the same as configuration 2 except that monthly aerosol fields and daily cloud fields come from the model SPRINTARS.

4. The "reading LMDz aerosols - SPRINTARS clouds" configuration: monthly aerosol fields are read from LMDz and daily cloud fields come from SPRINTARS.

5. The "reading SPRINTARS aerosols - LMDz clouds" configuration: monthly aerosol fields are read from SPRINTARS and daily cloud fields come from $\mathrm{LMDz}$

We use configuration 2 and not 1 for comparisons with the other configurations, because often only daily averaged fields are accessible from another model, such as SPRINTARS. The time step of $30 \mathrm{~min}$ in our LMDz model produces a higher variability in cloud fields, which introduces differences to a configuration reading in daily cloud fields. Similarly, to avoid differences coming from the different spatial resolution of the cloud fields read as input from the SPRINTARS model, these fields were regridded onto the LMDz resolution.

\subsubsection{The experiments}

With the default configuration, we first perform a simulation with the full 3-D aerosol distribution produced by default by the model. This baseline run will be referred to as the "reference simulation". For each of the five above-mentioned configurations, we then perform the four following experiments:

1. Experiment "AIB" (above,inside and below), with the full 3-D aerosol distribution produced by default by the model.

2. Experiment "ABV" (above), with aerosol optical depth set to zero except above the highest cloudy model layer.

3. Experiment "IN" (inside), with aerosol optical depth set to zero except between the lowest and the highest cloudy layers.

4. Experiment "BLW" (below), with aerosol optical depth set to zero except below the lowest cloudy level.
For these four experiments the optical depth is also set to zero in completely clear columns so that the AIB result can be directly compared to the sum of the ABV+IN+BLW experiments.

We determine the lowest and highest cloud levels at each model time step using cloud fraction and cloud extinction thresholds together. A no-cloud state is defined for the grid cell where cloud fraction is below a threshold of 0.001 or cloud extinction is below a threshold of $0.01 \mathrm{~km}^{-1}$, a value that is three orders of magnitude smaller than the typical observed cloud extinction coefficients (Li et al., 2011). Starting from the lowest model layer, we check whether the cloud fraction and extinction are larger than the corresponding thresholds. If the condition is fulfilled for at least one level, the column is considered (partially) cloudy and the first level that fulfills the condition is taken as the cloud bottom. Then, the same check is effectuated for the same column, starting from uppermost model level, to find the cloud top. Multilayer clouds are not identified with this method, and the experiment IN incorporates both aerosols inside a cloud and embedded in multi-layer clouds. Once the cloud top and bottom are identified at any time step and location, aerosol optical depths are set to zero in different portions of the column for the different experiments according to points (1) to (4). Setting aerosol optical depth to zero is equivalent to "eliminating" those aerosols, at least in regard to flux and forcing computations. The fluxes are computed in the model for each layer separately by use of the layer aerosol transmittance and reflectance, which assume their clear-sky values ( 1 and 0 , respectively) for aerosol optical depth set to zero. In the experiments AIB, ABV, IN and BLW, we set aerosol optical depths to zero if the column is completely clear, so that the distributions ABV, IN and BLW of aerosol optical depth sum up to that of AIB. The difference in total optical depth brought about by this correction with respect to the reference simulation (full 3-D aerosol distribution) will be discussed below in Sect. 4.

Note that our method of eliminating the radiative effect of the aerosol in parts of the column also implicitly changes the effective single-scattering albedo and asymmetry parameter of the aerosol, since composition and aerosol size differs in between vertical layers of the atmosphere. It is beyond the scope of this study to investigate separately the impact of vertical position and vertical variations in intensive aerosol optical properties.

The combination of the five configurations and the four experiments plus the reference simulation of the proposed method constitutes an ensemble of 21 runs.

\subsubsection{New options implemented in the LMDz radiative module}

In a GCM the feedbacks of aerosols and clouds on meteorological fields (see Sect. 3.2) prevent us from clearly interpreting the forcing differences among runs. Simulations with 
Table 2. Characteristic properties of the reference simulation using the default configuration of LMDz with the full aerosol distribution, (above, inside, below clouds, including the area with completely clear columns). "BC" stands for black carbon, "SO 4 " for sulfate, "POM" for particulate organic matter, "DUST" for mineral dust, "SS" for sea salt, "AER" for forcing diagnostics established using instantaneous, total aerosol optical properties, and "SUM" for arithmetic sum of values from individual aerosol species diagnostics. AOD stands for all-sky aerosol optical depth at $550 \mathrm{~nm}$ wavelength; AOD*, the average optical depth when excluding completely clear columns; CLT" ${ }^{\#}$, effective cloud fraction (see text); RF, direct radiative forcing against an aerosol-free atmosphere; NRF, RF normalized to AOD; "CS", clear sky; "CL", cloudy sky only; and "AS", all sky. Cloud mask hypothesis derived all-sky forcings $\mathrm{RF}_{\mathrm{AS}}^{*}=(1-\mathrm{CLT}) \cdot \mathrm{RF}_{\mathrm{CS}}$.

\begin{tabular}{|c|c|c|c|c|c|c|c|}
\hline & $\mathrm{BC}$ & $\mathrm{SO}_{4}$ & POM & DUST & SS & AER & SUM \\
\hline AOD [1] & $2.71 \times 10^{-3}$ & $3.96 \times 10^{-2}$ & $1.77 \times 10^{-2}$ & $2.67 \times 10^{-2}$ & $3.89 \times 10^{-2}$ & 0.126 & 0.126 \\
\hline $\mathrm{AOD}^{*}[1]$ & $2.37 \times 10^{-3}$ & $3.59 \times 10^{-2}$ & $1.61 \times 10^{-2}$ & $1.84 \times 10^{-2}$ & $3.74 \times 10^{-2}$ & 0.110 & 0.110 \\
\hline Burden $\left[\mathrm{mg} \mathrm{m}^{-2}\right]$ & 0.288 & 3.23 & 2.30 & 34.6 & 38.1 & 78.5 & 78.5 \\
\hline $\mathrm{CLT}^{\#}[\%]$ & $39 \%$ & $44 \%$ & $41 \%$ & $30 \%$ & $58 \%$ & $47 \%$ & $39 \%$ \\
\hline \multicolumn{8}{|l|}{ Forcings } \\
\hline $\mathrm{RF}_{\mathrm{CS}}\left[\mathrm{W} \mathrm{m}{ }^{-2}\right]$ & 0.280 & -0.730 & -0.253 & -0.473 & -0.913 & -2.39 & -2.09 \\
\hline $\mathrm{RF}_{\mathrm{CL}}\left[\mathrm{W} \mathrm{m}^{-2}\right]$ & 0.425 & -0.190 & 0.031 & -0.130 & -0.121 & -0.101 & 0.0146 \\
\hline $\mathrm{RF}_{\mathrm{AS}}\left[\mathrm{W} \mathrm{m}^{-2}\right]$ & 0.378 & -0.466 & -0.119 & -0.342 & -0.428 & -1.19 & -0.979 \\
\hline $\mathrm{RF}_{\mathrm{AS}}^{*}\left[\mathrm{~W} \mathrm{~m}^{-2}\right]$ & 0.17 & -0.41 & -0.15 & -0.33 & -0.38 & -1.27 & \\
\hline \multicolumn{8}{|l|}{ Forcing Efficiencies } \\
\hline $\mathrm{NRF}_{\mathrm{CS}}\left[\mathrm{W} \mathrm{m}^{-2} / 1\right]$ & 104 & -18.4 & -14.3 & -17.7 & -23.5 & -19.0 & I \\
\hline $\mathrm{NRF}_{\mathrm{CL}}\left[\mathrm{W} \mathrm{m}{ }^{-2}\right]$ & 157 & -4.79 & 1.75 & -4.89 & -3.11 & -0.801 & I \\
\hline
\end{tabular}

different spatial distributions of aerosol would not be comparable if feedbacks on cloud, wind, temperature and relative humidity fields took place. Furthermore, we want to isolate here the effect of cloud layers on the direct aerosol radiative forcing without having additional microphysical and dynamical interactions (indirect and semi-direct effects). To achieve these objectives, in LMDz we have implemented the options to

1. read as input cloud fields and

2. switch off the feedbacks from aerosols on the meteorology and use two different cloud fields, one for the diagnostics of radiative TOA forcing and the other for the meteorology.

To compute forcing with arbitrary cloud fields (option 1), we added a routine in the model that reads daily fields of cloud optical depths and cloud fractions of any origin.

To deactivate the aerosol feedback on meteorology (option 2), we call the radiation computations twice: once with the aerosol fields (to diagnose forcings) and once without any aerosol (to compute the feedback of default cloud radiative fluxes on meteorology). The latter means that we neglect all aerosol feedback on meteorology and climate, which would appear through modification of the radiative budget or the indirect/semi-direct effect.

Concerning cloud feedback on meteorology, we cannot simply "switch them off" as we do for aerosols. Cloud impacts on the thermodynamical balance of the atmosphere are important and we have to take them into account to have re- alistic temperature and humidity fields. Nevertheless, we do not wish to get a different cloud feedback for each configuration we use. In the three configurations default, reading LMDz and reading SPRINTARS, three different cloud fields are used for diagnostic flux computations: the online cloud field produced by default by the model, the daily averaged cloud field as output from the default configuration, and the SPRINTARS daily averaged cloud field, respectively.

To avoid three different feedbacks on meteorology, we introduced a double call to the radiation scheme in the model in order to compute all-sky fluxes, one used for meteorology, the other used for forcing computations: the first call uses the optical properties of the clouds that are produced interactively by the model in combination with zero aerosol. These clouds are the same for all the configurations/experiments, as the host model LMDz remains unchanged. The second call to the radiation scheme for cloudy-sky fluxes is done with the optical properties of the read-in cloud fields. The fluxes obtained as such are representative of the particular configuration, and we use these fluxes to diagnose all forcings.

With the implementation of these new options in the host model, all the meteorological fields are identical in the 21 runs we perform, but we can still diagnose different forcings due to different clouds and aerosols fields. We checked that "interactively computed" cloud fields, as well as temperature and humidity fields, are exactly the same for all of our runs (not shown). 

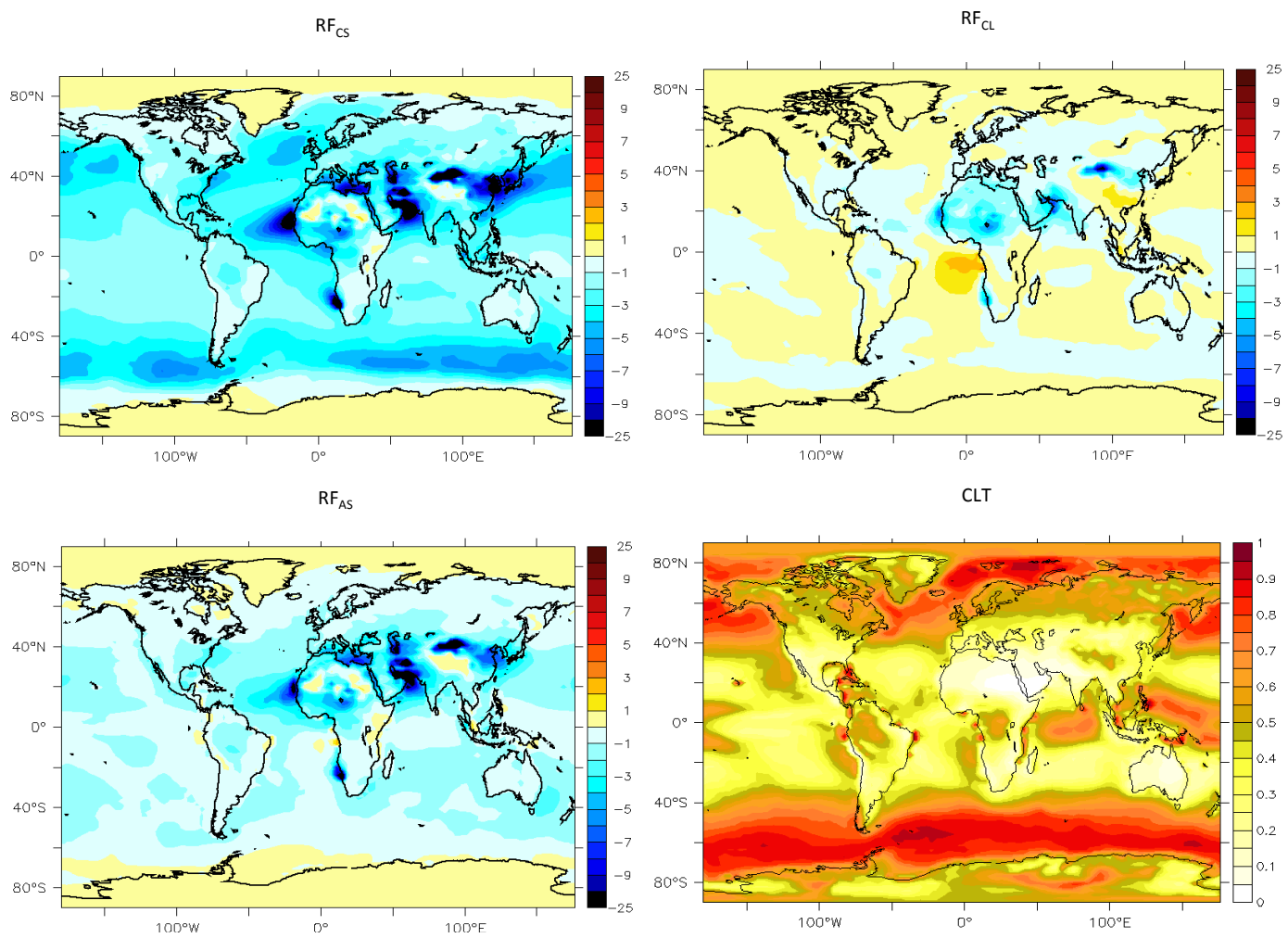

Fig. 2. All-aerosol (AER) radiative forcing in clear-sky $\left(\mathrm{RF}_{\mathrm{CS}}\left(\mathrm{W} \mathrm{m}^{-2}\right)\right.$, top left), cloudy-sky $\left(\mathrm{RF}_{\mathrm{CL}}\left(\mathrm{W} \mathrm{m}^{-2}\right)\right.$, top right) and all-sky $\left(\mathrm{RF}_{\mathrm{AS}}\right.$ $\left(\mathrm{W} \mathrm{m}^{-2}\right)$, bottom left) conditions. Bottom right: cloud fraction (CLT(1)).

\section{Results}

\subsection{Clear-sky and cloudy-sky TOA forcing in the refer- ence simulation}

In this section we discuss the TOA forcing and forcing efficiencies obtained for the full model run in the default configuration, our reference simulation. Table 2 shows the average values of optical depth, burden and clear-, cloudy- and all-sky TOA forcings, while Fig. 2 shows the spatial distribution of these latter forcings and the cloud fraction. Note again that, for simplicity and to limit the numbers of experiments, we have defined and computed forcing here as the sum of anthropogenic and natural direct aerosol radiative effects measured against a zero aerosol background in the radiative computations.

The total aerosol TOA forcing using the total aerosol optical properties (AER) is $-2.39 \mathrm{~W} \mathrm{~m}^{-2}$ in clear-sky conditions and $-1.19 \mathrm{~W} \mathrm{~m}^{-2}$ in all-sky conditions. All of the species except for BC exhibit negative top-of-the-atmosphere forcing. Total sulfate all-sky forcing is $-0.47 \mathrm{~W} \mathrm{~m}^{-2}$, which is in the range of the anthropogenic forcing values recently found by Myhre et al. (2013) $\left(-0.11\right.$ to $\left.-0.48 \mathrm{~W} \mathrm{~m}^{-2}\right)$, in particular when accounting for a $20 \%$ natural contribution. The total BC TOA forcing of $+0.38 \mathrm{~W} \mathrm{~m}^{-2}$ is considerably lower than the total BC estimated by Bond et al. (2013) $\left(+0.88 \mathrm{~W} \mathrm{~m}^{-2}\right)$, mainly due to differences in emissions (with lower emissions assumed in this work). This forcing corresponds to the range of anthropogenic fossil fuel and biofuel $\mathrm{BC}$ forcing reported by Myhre et al. $(2013)\left(+0.05\right.$ to $\left.+0.37 \mathrm{~W} \mathrm{~m}^{-2}\right)$, where similar emissions where assumed. The cloud fraction given in Table $2\left(\mathrm{CLT}^{\#}\right)$ corresponds to the mean of the monthly cloud fraction field weighted by the clear-sky forcing field. Figure 2 indicates higher cloud fractions in the marine regions with high sea salt burden (and hence sea salt clear-sky forcing) than in desert regions with higher dust burden.

Table 2 also reveals the importance of the cloudy-sky TOA forcing $\left(\mathrm{RF}_{\mathrm{CL}}\right)$, in particular for $\mathrm{BC}$, reflected by its magnitude and forcing efficiency. Cloudy-sky forcings are quite different from the corresponding clear-sky values for all species. If the clouds had no effect on the aerosols forcing, then the clear-sky and cloudy-sky aerosol forcings would be the same. Note that the cloudy-sky forcings reported in Table 2 are always more positive (or less negative) than the corresponding clear-sky forcings. POM cloudy-sky forcing even changes sign with respect to the clear-sky value.

Table 2 shows the all-sky TOA forcing estimated with a simple "cloud mask" hypothesis. Here we use annual fields of clear-sky forcing and cloud fraction: $\mathrm{RF}_{\mathrm{AS}}^{*}=(1-$ $\left.\mathrm{CLT}^{\#}\right) \mathrm{RF}_{\mathrm{CS}}$. The simple cloud-mask approximation gives all-sky forcing values that differ significantly from the "true" ones. In particular, a value of $\mathrm{BC}$ positive forcing that is 
Table 3. Optical depth and forcings in four experiments with aerosols above+inside+below clouds (AIB), only above (ABV), only inside (IN) and only below clouds (BLW) using the default configuration. Averages exclude completely clear columns. Abbreviations as in Table 2.

\begin{tabular}{|c|c|c|c|c|c|c|c|}
\hline & $\mathrm{BC}$ & $\mathrm{SO}_{4}$ & POM & DUST & SS & AER & SUM \\
\hline \multicolumn{8}{|c|}{ AIB Experiment } \\
\hline $\mathrm{AOD}^{*} 1000[1]$ & 2.4 & 35.9 & 16.1 & 18.4 & 37.4 & 110 & 110 \\
\hline $\mathrm{RF}_{\mathrm{CS}}\left[\mathrm{W} \mathrm{m}^{-2}\right]$ & +0.279 & -0.725 & -0.252 & -0.464 & -0.910 & -2.370 & -2.070 \\
\hline $\mathrm{RF}_{\mathrm{CL}}\left[\mathrm{W} \mathrm{m}{ }^{-2}\right]$ & +0.424 & -0.189 & +0.031 & -0.130 & -0.121 & -0.100 & +0.015 \\
\hline$\left(\mathrm{RF}_{\mathrm{CL}}-\mathrm{RF}_{\mathrm{CS}}\right) /\left|\mathrm{RF}_{\mathrm{CS}}\right|$ & $52 \%$ & $74 \%$ & $112 \%$ & $72 \%$ & $87 \%$ & $96 \%$ & \\
\hline $\mathrm{RF}_{\mathrm{AS}}\left[\mathrm{W} \mathrm{m}^{-2}\right]$ & +0.375 & -0.463 & -0.119 & -0.334 & -0.427 & -1.180 & -0.968 \\
\hline $\mathrm{NRF}_{\mathrm{CS}}\left[\mathrm{W} \mathrm{m}{ }^{-2}\right]$ & +118 & -20.2 & -15.6 & -25.2 & -24.4 & -21.5 & I \\
\hline $\mathrm{NRF}_{\mathrm{CL}}\left[\mathrm{W} \mathrm{m}{ }^{-2}\right]$ & +178 & -5.3 & +1.9 & -7.0 & -3.2 & -0.9 & I \\
\hline \multicolumn{8}{|c|}{ ABV Experiment } \\
\hline $\mathrm{AOD}^{*} 1000[1]$ & 0.69 & 10.6 & 4.83 & 2.17 & 2.51 & 20.8 & 20.8 \\
\hline $\mathrm{RF}_{\mathrm{CS}}\left[\mathrm{W} \mathrm{m}^{-2}\right]$ & +0.088 & -0.227 & -0.064 & -0.054 & -0.033 & -0.349 & -0.289 \\
\hline $\mathrm{RF}_{\mathrm{CL}}\left[\mathrm{W} \mathrm{m}^{-2}\right]$ & +0.231 & -0.057 & +0.059 & +0.025 & +0.014 & +0.257 & +0.272 \\
\hline$\left(\mathrm{RF}_{\mathrm{CL}}-\mathrm{RF}_{\mathrm{CS}}\right) /\left|\mathrm{RF}_{\mathrm{CS}}\right|$ & $163 \%$ & $75 \%$ & $192 \%$ & $146 \%$ & $142 \%$ & $174 \%$ & \\
\hline $\mathrm{RF}_{\mathrm{AS}}\left[\mathrm{W} \mathrm{m}^{-2}\right]$ & +0.163 & -0.130 & +0.001 & -0.012 & -0.008 & -0.022 & -0.008 \\
\hline $\mathrm{NRF}_{\mathrm{CS}}\left[\mathrm{W} \mathrm{m}{ }^{-2}\right]$ & +126 & -21.3 & -13.2 & -24.8 & -13.2 & -16.7 & / \\
\hline $\mathrm{NRF}_{\mathrm{CL}}\left[\mathrm{W} \mathrm{m}{ }^{-2}\right]$ & +333 & -5.4 & +12.2 & +11.5 & +5.7 & +12.3 & l \\
\hline \multicolumn{8}{|c|}{ IN Experiment } \\
\hline $\mathrm{AOD}^{*} 1000[1]$ & 0.85 & 16.4 & 6.50 & 4.68 & 19.2 & 47.6 & 47.6 \\
\hline $\mathrm{RF}_{\mathrm{CS}}\left[\mathrm{W} \mathrm{m}^{-2}\right]$ & +0.089 & -0.264 & -0.084 & -0.126 & -0.446 & -0.993 & -0.831 \\
\hline $\mathrm{RF}_{\mathrm{CL}}\left[\mathrm{W} \mathrm{m}{ }^{-2}\right]$ & +0.146 & -0.048 & +0.018 & -0.002 & -0.042 & +0.019 & +0.071 \\
\hline$\left(\mathrm{RF}_{\mathrm{CL}}-\mathrm{RF}_{\mathrm{CS}}\right) /\left|\mathrm{RF}_{\mathrm{CS}}\right|$ & $64 \%$ & $82 \%$ & $121 \%$ & $98 \%$ & $91 \%$ & $102 \%$ & \\
\hline $\mathrm{RF}_{\mathrm{AS}}\left[\mathrm{W} \mathrm{m}^{-2}\right]$ & +0.120 & -0.131 & -0.030 & -0.057 & -0.156 & -0.358 & -0.254 \\
\hline $\mathrm{NRF}_{\mathrm{CS}}\left[\mathrm{W} \mathrm{m}^{-2}\right]$ & +104 & -16.1 & -12.9 & -26.8 & -23.3 & -20.9 & I \\
\hline $\mathrm{NRF}_{\mathrm{CL}}\left[\mathrm{W} \mathrm{m}^{-2}\right]$ & +171 & -2.9 & 2.7 & -0.52 & -2.2 & +0.4 & I \\
\hline \multicolumn{8}{|c|}{ BLW Experiment } \\
\hline AOD*1000 [1] & 0.83 & 8.91 & 4.78 & 11.5 & 15.7 & 41.8 & 41.8 \\
\hline $\mathrm{RF}_{\mathrm{CS}}\left[\mathrm{W} \mathrm{m}^{-2}\right]$ & +0.068 & -0.171 & -0.085 & -0.193 & -0.418 & -0.895 & -0.800 \\
\hline $\mathrm{RF}_{\mathrm{CL}}\left[\mathrm{W} \mathrm{m}{ }^{-2}\right]$ & +0.036 & -0.072 & -0.041 & -0.138 & -0.089 & -0.353 & -0.303 \\
\hline$\left(\mathrm{RF}_{\mathrm{CL}}-\mathrm{RF}_{\mathrm{CS}}\right) /\left|\mathrm{RF}_{\mathrm{CS}}\right|$ & $-47 \%$ & $58 \%$ & $52 \%$ & $28 \%$ & $79 \%$ & $61 \%$ & \\
\hline $\mathrm{RF}_{\mathrm{AS}}\left[\mathrm{W} \mathrm{m}^{-2}\right]$ & +0.057 & -0.136 & -0.070 & -0.171 & -0.242 & -0.637 & -0.561 \\
\hline $\mathrm{NRF}_{\mathrm{CS}}\left[\mathrm{W} \mathrm{m}^{-2}\right]$ & +82 & -19.2 & -17.8 & -16.7 & -26.7 & -21.4 & I \\
\hline $\mathrm{NRF}_{\mathrm{CL}}\left[\mathrm{W} \mathrm{m} \mathrm{m}^{-2}\right]$ & +44 & -8.1 & -8.6 & -11.9 & -5.7 & -8.5 & I \\
\hline
\end{tabular}

much too low is observed, showing that half of the black carbon forcing can be attributed to effects other than masking in cloudy regions.

\subsection{TOA forcing contributions from below, above and within clouds}

Where is the redistribution of radiative energy located within the vertical column of the cloudy sky? Further insight into the question comes from the results of the experiments AIB, $\mathrm{ABV}, \mathrm{IN}$ and BLW using the default configuration. Table 3 gives the values of AOD*, TOA forcings and forcing efficiencies for these experiments. The cloud level information in each column at any given moment is used to obtain global av- erages. Note again that we have excluded the grid columns in which no clouds are present from the averages (see Sect. 3). Excluding these columns has a small impact on the results. In Table 2, aerosol optical depths in the full-scale reference simulation are compared to the AOD* of the AIB experiment, i.e. the aerosol optical depth obtained when excluding completely clear columns. They are only about $10 \%$ higher, except for dust, where the difference is found to be $31 \%$. This is due to high dust loads appearing in very dry regions, where even our coarse GCM simulates no clouds and where thus the corresponding AOD is excluded from being taken into account for a global average AOD*.

The example of $\mathrm{BC}$ allows the effect of the vertical position of aerosol on clear-sky forcing efficiency to be 
appreciated. The horizontal distribution of $\mathrm{BC}$ optical depth and the fractions of $\mathrm{BC}$ above, inside and below clouds are given in Fig. 3. BC clear-sky forcing efficiency $\left(\mathrm{NRF}_{\mathrm{CS}}\right)$ equals on average $118 \mathrm{~W} \mathrm{~m}^{-2}$ per unit optical depth in the AIB experiment (Table 3). It varies from 82 to $126 \mathrm{~W} \mathrm{~m}^{-2}$ when passing from the experiment BLW to ABV. In the $\mathrm{BC}_{\mathrm{ABV}}$ experiment, absorption of shortwave radiation is therefore $54 \%$ stronger than in the $\mathrm{BC}_{\mathrm{BLW}}$ experiment. One reason is that at higher altitudes, atmospheric molecules intercept less of the incoming radiation before it can interact with BC. This model behaviour is in agreement with Haywood and Ramaswamy (1998) and Samset and Myhre (2011), but we quantify here the effect for three distinct portions of the column. For comparison with cloudy sky, it is interesting to note from Table 3 that cloudy-sky forcing efficiency $\left(\mathrm{NRF}_{\mathrm{CL}}\right)$ is $178 \mathrm{~W} \mathrm{~m}^{-2}$ per unit optical depth in the AIB experiment, and varies from 44 to $333 \mathrm{~W} \mathrm{~m}^{-2}$ when passing from below to above clouds; that is, $\mathrm{BC}_{\mathrm{ABV}}$ is $650 \%$ more efficient than the $\mathrm{BC}_{\mathrm{BLW}}$ in absorbing incoming shortwave radiation when clouds are present. Notice that the hygroscopic growth of the aerosols may be responsible for an increased optical depth and forcing (see Sect. 3.1), while the forcing efficiency should remain unaffected. The higher contribution to forcing from aerosols near the surface (where humidity is generally higher) has potentially influenced the difference in the values of RF from below, inside and above clouds. As we are interested in the actual aerosols' optical properties and forcings (i.e. accounting for hygroscopicity), this does not constitute a problem in the analysis. We further inspect the cloudy-sky forcing and forcing efficiency and compare them to the clear-sky counterparts. The relative difference $\left(\mathrm{RF}_{\mathrm{CL}}-\mathrm{RF}_{\mathrm{CS}}\right) /\left|\mathrm{RF}_{\mathrm{CS}}\right|$ in Table 3 quantifies the enhancement (if it has the same sign as $\mathrm{RF}_{\mathrm{CS}}$ ) or attenuation (if opposite sign) of the aerosol forcing due to the presence of clouds. This relative difference has the advantage of being weakly sensitive to aerosol horizontal distribution, as cloudy- and clear-sky forcings are similarly influenced by surface albedo.

As for the reference simulation (see Sect. 4.1), for the AIB, $\mathrm{ABV}$ and IN experiments, the relative differences $\left(\mathrm{RF}_{\mathrm{CL}}-\right.$ $R F_{C S}$ ) $/\left|R_{C S}\right|$ are positive for all aerosol species (see Table 3). This means that all aerosol forcings are attenuated except for BC, since the clear-sky forcing is positive for BC and negative for all the other species. Except for sulfate, these relative differences in the ABV experiment are much more important than in AIB. For black carbon, for example, the forcing enhancement by clouds is $52 \%$ for the AIB and $163 \%$ for the $\mathrm{ABV}$ experiments. This signifies that the region above the clouds dominates the cloudy-sky forcing. In the ABV experiment, POM, DUST and SS even change sign (become positive) when passing from clear to cloudy sky. This positive cloudy-sky forcing reflects that even if the considered species is not absorbing at all (such as sea salt), more incoming shortwave radiation is trapped in between the aerosol and the cloud layer by the slightly absorbing air molecules. In the
BLW experiment, all $\mathrm{RF}_{\mathrm{CL}}-\mathrm{RF}_{\mathrm{CS}}$ differences are positive except for $\mathrm{BC}$, meaning that all forcings are attenuated below clouds. Interestingly the cloudy-sky aerosol forcing below clouds does not become zero, indicating that thin clouds and cloud overlap assumptions in the model allow for an aerosol effect even when present below the lowest cloud layer. For black carbon, the TOA forcing below clouds is attenuated by $47 \%$ with respect to its clear-sky counterpart (Table 3 , $\left(\mathrm{RF}_{\mathrm{CL}}-\mathrm{RF}_{\mathrm{CS}}\right) /\left|\mathrm{RF}_{\mathrm{CS}}\right|$ for BLW experiment). For the experiment IN (BC between the lowest and the highest cloudy levels) the two effects of TOA forcing attenuation and enhancement coexist, but the second one is prevailing. The relative difference $\left(\mathrm{RF}_{\mathrm{CL}}-\mathrm{RF}_{\mathrm{CS}}\right) /\left|\mathrm{RF}_{\mathrm{CS}}\right|$ is indeed $64 \%$ for $\mathrm{BC}$ in the IN experiment, and the cloudy-sky forcing efficiency increases from 44 to $171 \mathrm{~W} \mathrm{~m}^{-2} \tau^{-1}$ when passing from BLW to IN experiments (see Table $3, \mathrm{NRF}_{\mathrm{CL}}$ rows). This enhancing effect for $\mathrm{BC}$ within clouds may depend on the specific configuration of the clouds: for example, low clouds of high albedo superposed by high optically thin clouds, and BC between them. Zarzycki and Bond (2010) have shown that cloud type is an important factor in the enhancement of BC forcing.

The three experiments seen together clearly show that the cloudy-sky forcing efficiencies are much more sensitive to the vertical position of the aerosol than their clear-sky counterpart. Cloudy-sky BC forcing efficiency ABV versus BLW is different by a factor of 8 , while clear-sky forcing $\mathrm{ABV}$ versus BLW is only enhanced by a factor of 1.5 .

\subsection{BC TOA forcing sensitivity to variable black carbon and cloud fields}

This section is dedicated to the application of our method to the interpretation of inter-model spread in black carbon forcing estimates. We compare four possible different configurations and compute from monthly aerosol and daily cloud fields the black carbon radiative forcing. For this we use LMDz and SPRINTARS model outputs as described above and can be found as section headers in Table 4 . The different experiments AIB, IN, BLW and ABV have been performed for all four configurations. Only results for black carbon are analysed because it gives the largest contribution to cloudysky aerosol forcing and shows the largest variation of forcing and forcing efficiency passing from clear to cloudy sky and from below to above clouds.

The configuration reading $\mathrm{LMDz}$ and the configuration used in Sect. 4.2 differ in that daily mean cloud fields from the LMDz reference simulation are used here instead of the instantaneous model cloud fields (see Sect. 3.4.1). There are more partially cloudy areas in daily mean fields. As a result, small differences appear for all parameters (compare BC column of Table 3 with "Reading LMDz configuration" of Table 4). The differences in cloudy-sky BC forcing are of the order of $5 \%$ and less than $1 \%$ in clear-sky conditions. 
Table 4. Black carbon optical depth $\left(\mathrm{AOD}_{\mathrm{BC}}\right)$ and associated forcings for four experiments (as detailed in Table 3 ) and four configurations in which monthly LMDz and SPRINTARS aerosol and cloud fields are read. Abbreviations as in Table 2.

\begin{tabular}{|c|c|c|c|c|}
\hline Experiments: & AIB & $\mathrm{ABV}$ & IN & BLW \\
\hline \multicolumn{5}{|c|}{ Reading LMDz configuration } \\
\hline $\mathrm{AOD}_{\mathrm{BC}}^{*} 1000[1]$ & 2.47 & 0.72 & 0.99 & 0.75 \\
\hline $\mathrm{RF}_{\mathrm{CS}}\left[\mathrm{W} \mathrm{m}{ }^{-2}\right]$ & 0.279 & 0.092 & 0.096 & 0.065 \\
\hline $\mathrm{RF}_{\mathrm{AS}}\left[\mathrm{W} \mathrm{m}^{-2}\right]$ & 0.372 & 0.164 & 0.124 & $5.7110^{-2}$ \\
\hline $\mathrm{RF}_{\mathrm{CL}}\left[\mathrm{W} \mathrm{m}^{-2}\right]$ & 0.442 & 0.237 & 0.153 & $3.79 \times 10^{-2}$ \\
\hline $\mathrm{NRF}_{\mathrm{CS}}\left[\mathrm{W} \mathrm{m}{ }^{-2}\right]$ & 113 & 127 & 96.6 & 86.5 \\
\hline $\mathrm{NRF}_{\mathrm{CL}}\left[\mathrm{W} \mathrm{m}{ }^{-2}\right]$ & 179 & 328 & 155 & 50 \\
\hline \multicolumn{5}{|c|}{ Reading SPRINTARS configuration } \\
\hline $\mathrm{AOD}_{\mathrm{BC}}^{*} 1000[1]$ & 2.32 & 0.75 & 1.24 & 0.33 \\
\hline $\mathrm{RF}_{\mathrm{CS}}\left[\mathrm{W} \mathrm{m}^{-2}\right]$ & 0.270 & 0.084 & 0.106 & 0.028 \\
\hline $\mathrm{RF}_{\mathrm{AS}}\left[\mathrm{W} \mathrm{m}^{-2}\right]$ & 0.351 & 0.147 & 0.127 & 0.025 \\
\hline $\mathrm{R}_{\mathrm{CL}}\left[\mathrm{W} \mathrm{m}^{-2}\right]$ & 0.440 & 0.237 & 0.157 & 0.015 \\
\hline $\mathrm{NRF}_{\mathrm{CS}}\left[\mathrm{W} \mathrm{m}{ }^{-2}\right]$ & 116 & 112 & 85.3 & 86.1 \\
\hline $\mathrm{NRF}_{\mathrm{CL}}\left[\mathrm{W} \mathrm{m}{ }^{-2}\right]$ & 190 & 318 & 127 & 44 \\
\hline \multicolumn{5}{|c|}{ Reading LMDz aerosols - SPRINTARS clouds configuration } \\
\hline $\mathrm{AOD}_{\mathrm{BC}}^{*} 1000[1]$ & 2.21 & 0.99 & 0.95 & 0.27 \\
\hline $\mathrm{RF}_{\mathrm{CS}}\left[\mathrm{W} \mathrm{m}{ }^{-2}\right]$ & 0.278 & 0.117 & 0.083 & 0.023 \\
\hline $\mathrm{RF}_{\mathrm{AS}}\left[\mathrm{W} \mathrm{m}^{-2}\right]$ & 0.383 & 0.208 & 0.101 & 0.020 \\
\hline $\mathrm{RF}_{\mathrm{CL}}\left[\mathrm{W} \mathrm{m}{ }^{-2}\right]$ & 0.500 & 0.329 & 0.126 & 0.012 \\
\hline $\mathrm{NRF}_{\mathrm{CS}}\left[\mathrm{W} \mathrm{m}{ }^{-2}\right]$ & 126 & 118 & 87 & 84.1 \\
\hline $\mathrm{NRF}_{\mathrm{CL}}\left[\mathrm{W} \mathrm{m}^{-2}\right]$ & 227 & 333 & 132 & 43.6 \\
\hline \multicolumn{5}{|c|}{ Reading SPRINTARS aerosols - LMDz clouds configuration } \\
\hline $\mathrm{AOD}_{\mathrm{BC}}^{*} 1000[1]$ & 2.58 & 0.51 & 1.18 & 0.89 \\
\hline $\mathrm{RF}_{\mathrm{CS}}\left[\mathrm{W} \mathrm{m}{ }^{-2}\right]$ & 0.271 & 0.062 & 0.107 & 0.078 \\
\hline $\mathrm{RF}_{\mathrm{AS}}\left[\mathrm{W} \mathrm{m}^{-2}\right]$ & 0.342 & 0.113 & 0.138 & 0.067 \\
\hline $\mathrm{RF}_{\mathrm{CL}}\left[\mathrm{W} \mathrm{m}^{-2}\right]$ & 0.383 & 0.164 & 0.163 & 0.043 \\
\hline $\mathrm{NRF}_{\mathrm{CS}}\left[\mathrm{W} \mathrm{m}{ }^{-2}\right]$ & 105 & 122 & 90.4 & 87.1 \\
\hline $\mathrm{NRF}_{\mathrm{CL}}\left[\mathrm{W} \mathrm{m}{ }^{-2}\right]$ & 148 & 321 & 138 & 48.7 \\
\hline
\end{tabular}

Such small differences even exist for global mean AOD, which is derived excluding completely cloud-free columns by setting AOD to zero there. As cloud fields for the default and reading LMDz configurations are instantaneous and daily averaged, respectively, aerosol optical depths are not exactly identical. The difference in optical depths between default and reading LMDz configurations amounts to about $4 \%$. This difference is small enough to consider the reading LMDz configuration representative of the default one, with the advantage of being unequivocally comparable to that of reading SPRINTARS. For SPRINTARS, only daily mean cloud fields were available.

A direct comparison of the two model inputs can be found in Table 4 as global averages of TOA forcings and forcing efficiencies for the reading LMDz and reading SPRINTARS configurations. We will denote as "relative difference":
(SPRINTARS value - $\mathrm{LMDz}$ value)/LMDz value. With this notation, in the case of the AIB experiment the two models differ by $-5 \%$ for BC optical depth, by $-3 \%$ in clear-sky forcing, by $-0.6 \%$ in cloudy-sky forcing and by $-6 \%$ in allsky forcing. Regionally the differences are much larger and can exceed $100 \%$ (Fig. 5). Figure 4 represents the BC optical depths from reading LMDz and the differences to reading SPRINTARS, for the experiments AIB, ABV, IN, BLW. Black carbon in SPRINTARS is less present at ground level and in continental regions, and has a higher fraction of total $\mathrm{AOD}_{\mathrm{BC}}$ in the in-cloud region except in a region in the Atlantic Ocean off Angola, where important negative differences of $\mathrm{AOD}_{\mathrm{BC}}$ (SPRINTARS value - LMDz value) are observed. $A_{O O D}$ differences are in general positive for the experiment $\mathrm{ABV}$, meaning that more $\mathrm{BC}$ is present above clouds for SPRINTARS. As a global average, the vertical profiles of $\mathrm{BC}$ and clouds are given in Fig. 6 for reading LMDz and reading SPRINTARS configurations, and AIB, $\mathrm{ABV}$, IN and BLW experiments.

Figure 5 shows the corresponding horizontal distribution patterns of clear-, cloudy- and all-sky forcings. Figure 5 illustrates that the regional differences between the two configurations can be very large, with larger differences for cloudy sky than for clear sky. This is not reflected by the abovementioned globally averaged differences. The differences in clear-sky forcings (Fig. 5, top right)closely reflect the differences in BC optical depth (Fig. 4, top right): SPRINTARS clear-sky forcing and optical depth is greater in eastern Asia and Indonesia and weaker in Africa and South America. Allsky forcing differences (Fig. 5, bottom right) are quite similar to the clear-sky ones, with larger positive differences. As regards cloudy-sky forcings, the highest positive values of the difference are found over the coast of western Africa, in eastern Asia and Indonesia, and over the seas they are more important than their clear-sky counterparts. The split of BC optical depth in the ABV, IN and BLW experiment (Fig. 4) helps in understanding this behaviour: SPRINTARS exceeds the LMDz cloudy-sky forcing in regions where BC optical depth above and within clouds are also higher in SPRINTARS, such as over eastern Asia and over the Atlantic Ocean far from the Angolan coastline. Near this coastline, SPRINTARS shows a significantly lower BC fraction within clouds (Fig. 4, IN row), which is producing the negative differences in cloudy-sky forcings observed in Fig. 5 (middle right-hand panel). This is in agreement with the prevailing enhancement effect when BC is found within clouds, as discussed in the previous section.

In general, regions with negligible clear-sky TOA forcing differences and important cloudy-sky forcing differences are related to a BC vertical distribution with the same load but a different vertical pattern. For SPRINTARS, a large part of the $\mathrm{BC}$ load is situated above the cloud top (see the positive values in Fig. 4, middle right-hand panel).

In the reading LMDz and reading SPRINTARS configurations, BC optical depth above clouds represents 29 and 


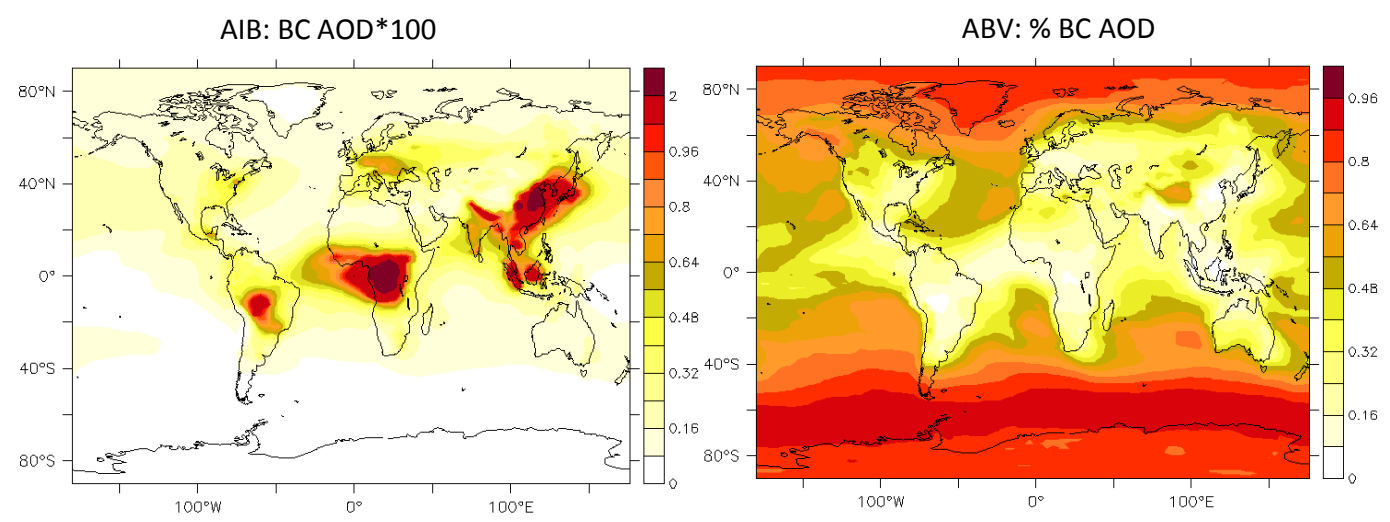

IN: \% BC AOD

BLW: \% BC AOD

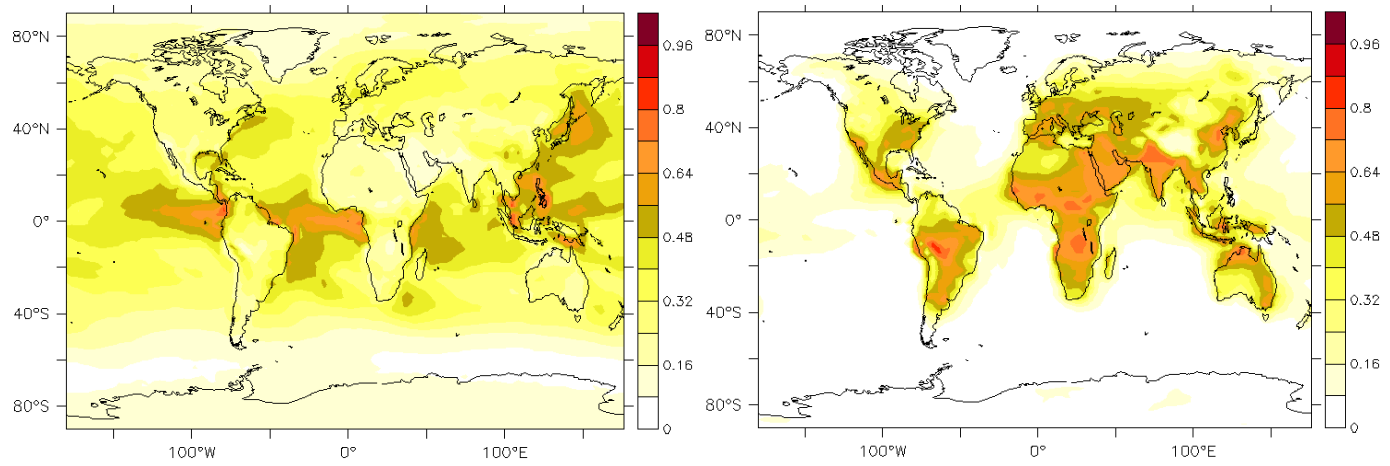

Fig. 3. BC optical depth distribution: BC AOD*100 for the AIB experiment (top left), percentage of BC AOD above clouds (ABV experiment, top right), percentage of BC AOD inside clouds (IN experiment, bottom left) and percentage of BC AOD below clouds (BLW experiment, bottom right).

$32 \%$ of the total, respectively, and its contribution to the total cloudy-sky BC TOA forcing amounts in both cases to $54 \%$ (Table 4). This reflects a significant nonlinearity between forcing and optical depth as a function of vertical position of $\mathrm{BC}$ with respect to clouds. For comparison, in clear sky, the $\mathrm{BC}$ of the $\mathrm{ABV}$ experiment contributes $33 \%$ to the clearsky forcing for LMDz and $31 \%$ for SPRINTARS. Overall the efficiency $\mathrm{NRF}_{\mathrm{CL}}$ for the AIB experiment is greater for SPRINTARS than for LMDz (190 compared to 179; see Table 4). The larger fraction of BC optical depth above but also within clouds for SPRINTARS is responsible for this difference. Altogether it appears that even if the two all-sky forcings are not so different, the contributions from different regions and height levels are composed in a complex manner.

We also have performed the two "crossed simulations" corresponding to the configurations reading LMDz aerosols - SPRINTARS clouds and reading SPRINTARS aerosols LMDz clouds (results are also shown in Table 4). Comparisons are in this way possible for two configurations of, for instance, reading LMDz aerosols. The changes in AOD values for corresponding experiments indicate that the clouds determine where aerosol is counted in our diagnostics, which excludes completely cloud-free columns. The overall BC cloudy-sky forcing efficiency is the highest for the reading
Table 5. Clouds characteristics for the default, reading LMDz and reading SPRINTARS configurations: cloud optical depth (COD) and 2-D cloud fraction (CLT).

\begin{tabular}{llll}
\hline & $\begin{array}{l}\text { Default } \\
\text { configuration }\end{array}$ & $\begin{array}{l}\text { Reading LMDz } \\
\text { configuration }\end{array}$ & $\begin{array}{l}\text { Reading SPRINTARS } \\
\text { configuration }\end{array}$ \\
\hline COD & 6.76 & 6.76 & 7.91 \\
CLT & 0.463 & 0.435 & 0.396 \\
\hline
\end{tabular}

SPRINTARS and reading LMDz aerosols - SPRINTARS clouds configuration, with values of 190 and $227 \mathrm{~W} \mathrm{~m}^{-2}$ per unit optical depth (Table 4, AIB column). This behaviour seems to be related to the vertical distribution of $\mathrm{BC}$ and clouds rather than to clouds characteristics.

Indeed, SPRINTARS clouds are optically thicker (see Table 5), and thus they have higher albedo (Twomey, 1974). If the clouds' albedo was the main reason for the model differences, BC aerosols above SPRINTARS clouds (optically thicker) would always have greater forcing efficiency than above LMDz clouds (optically thinner). Nevertheless, the two highest cloudy-sky normalized radiative efficiencies appear for LMDz aerosols above SPRINTARS clouds 

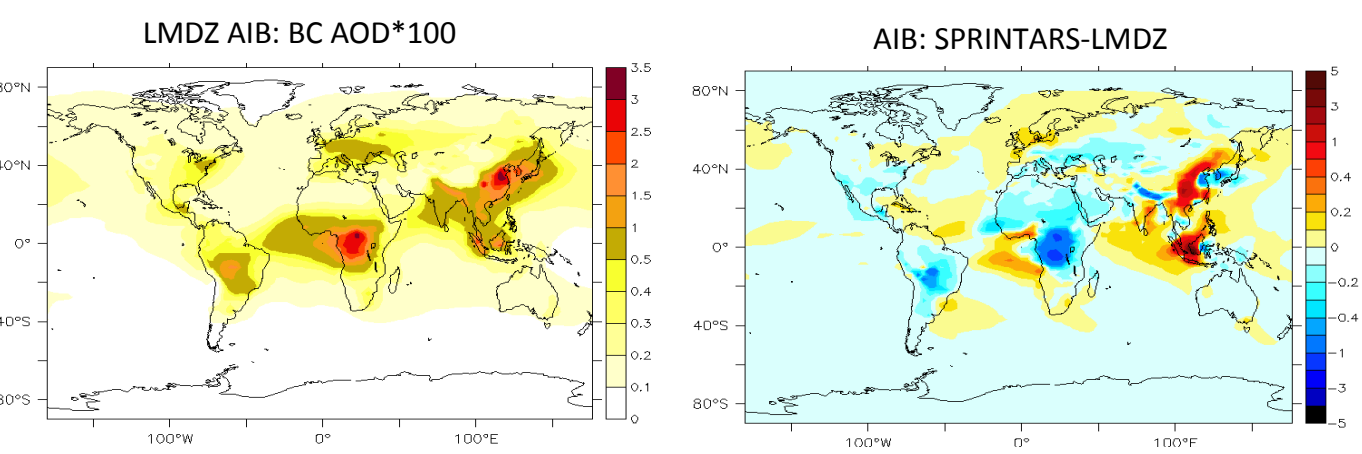

LMDZ ABV: BC AOD*100

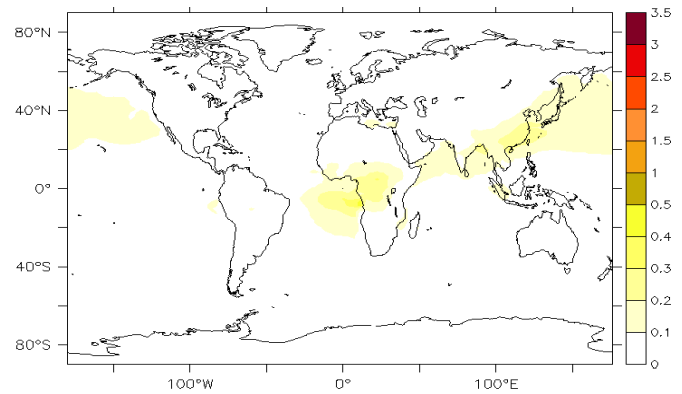

ABV: SPRINTARS-LMDZ

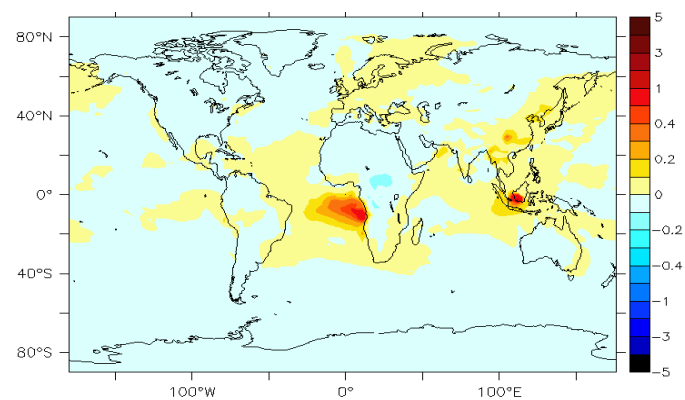

IN: SPRINTARS-LMDZ

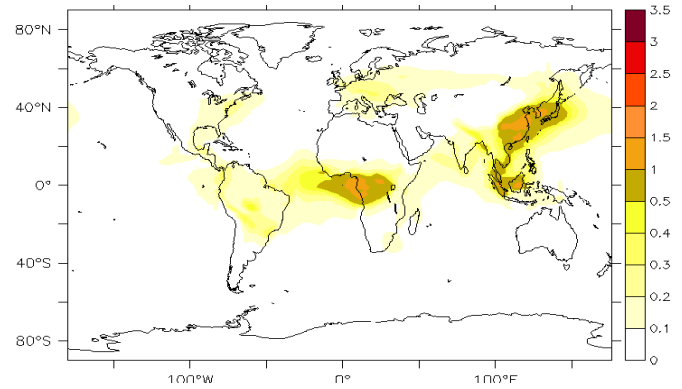

LMDZ BLW: BC AOD*100

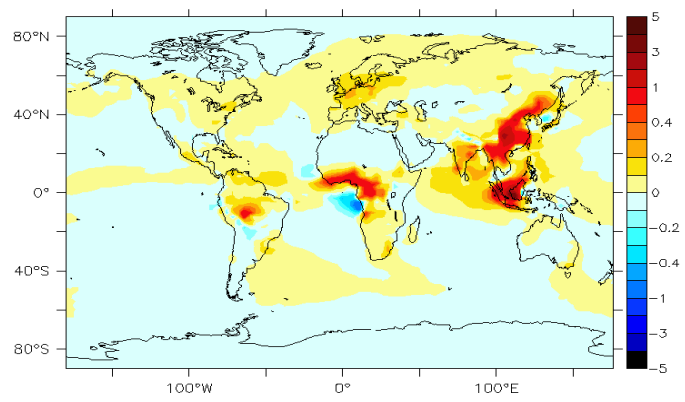

BLW: SPRINTARS-LMDZ
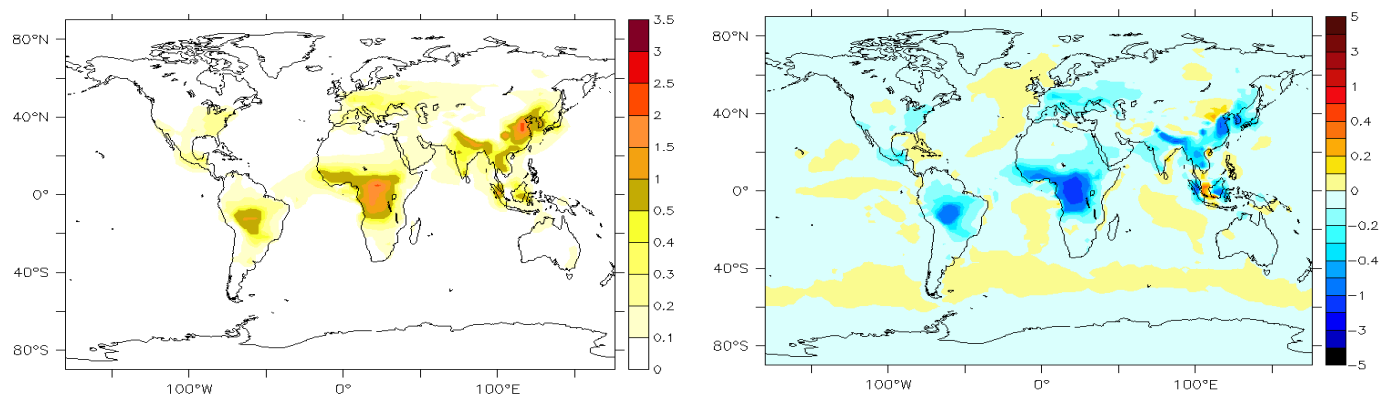

Fig. 4. Left column: reading LMDz values of BC optical depth (BC AOD). Right column: reading SPRINTARS minus reading LMDz values of BC AOD. Top to bottom: AIB, ABV, IN and BLW experiments. 

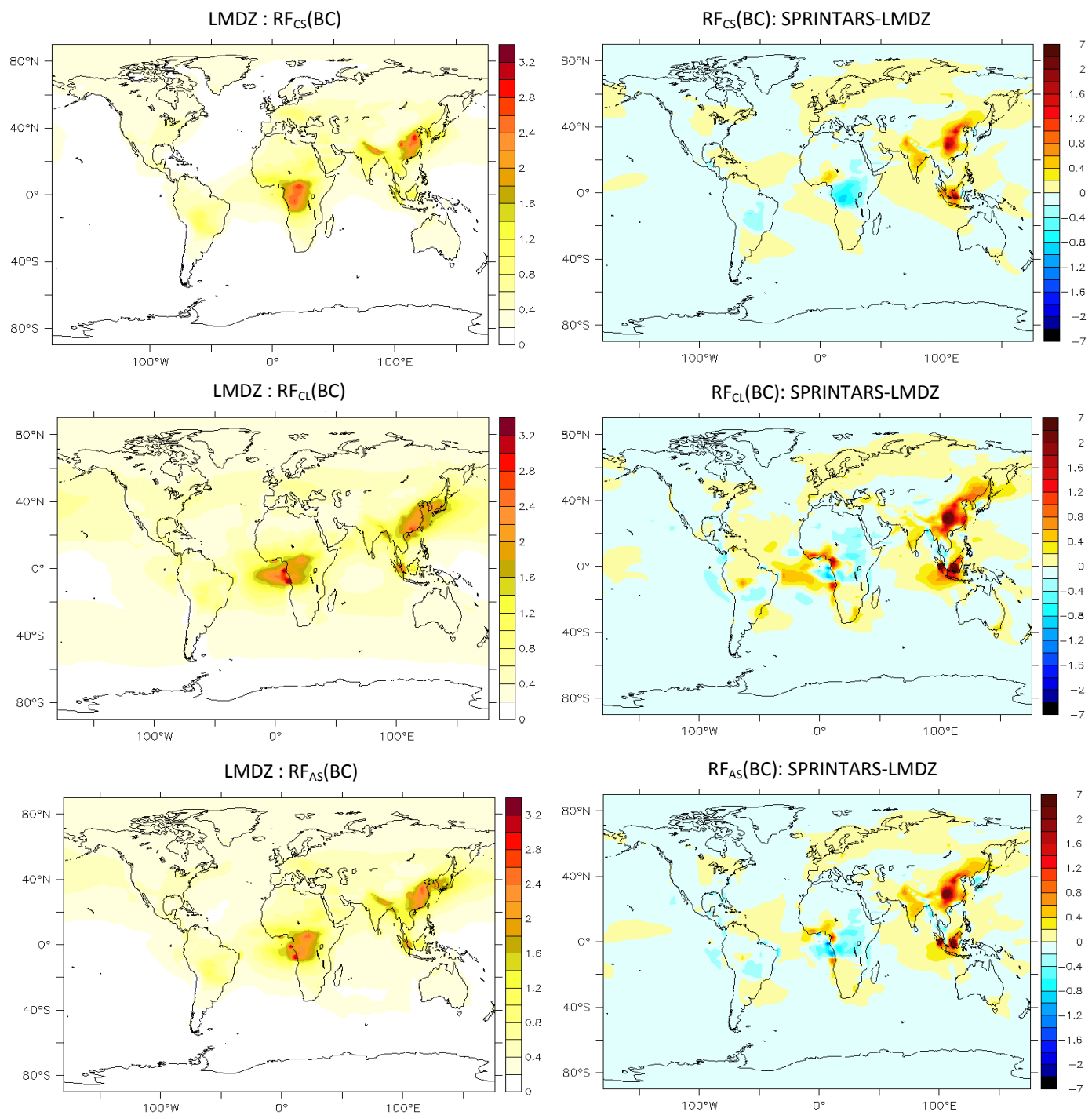

Fig. 5. Left column: reading LMDz values of BC forcings. Right column: reading SPRINTARS minus reading LMDz BC forcings. Top to bottom: clear-, cloudy- and all-sky values $\left(\mathrm{RF}_{\mathrm{CS}}, \mathrm{RF}_{\mathrm{CL}}, \mathrm{RF}_{\mathrm{AS}}\left[\mathrm{W} \mathrm{m}^{-2}\right]\right)$.

$\left(333 \mathrm{~W} \mathrm{~m}^{-2}\right)$ and above LMDz clouds $\left(328 \mathrm{~W} \mathrm{~m}^{-2}\right.$; see Table 4 , ABV column).

On the other hand, the overall $\mathrm{NRF}_{\mathrm{CL}}$ for the different configuration has the same behaviour as the fraction of $\mathrm{BC}$ above and within clouds. The two configurations reading SPRINTARS and reading LMDz aerosols - SPRINTARS clouds, for which the $\mathrm{NRF}_{\mathrm{CL}}$ is the highest, are also the ones that have the largest fraction of BC above and within clouds: 85 and $88 \%$ respectively, compared to 66 and $69 \%$ for the two other configurations.

We conclude that, for the range of clouds optical depths considered here, the enhancement of $\mathrm{BC}$ forcing by clouds is not primarily sensitive to cloud characteristics but instead much more to the fraction of $\mathrm{BC}$ above and within clouds. Note again that the $\mathrm{BC}$ optical properties are the same for both models since we are reading concentrations and compute optical properties during model run.

\section{Discussion}

\subsection{Role of clouds and aerosol vertical positions for black carbon TOA forcing}

The effects of clouds and BC-relative positions on BC forcing can be physically understood in the following way: when absorbing aerosols such as BC are above clouds, underlying clouds are more reflective than the underlying surface, so that their presence amplifies the positive forcing. For scattering aerosols, the fact that clouds are more reflective than the underlying surface determines a reduction of their negative 
LMDZ

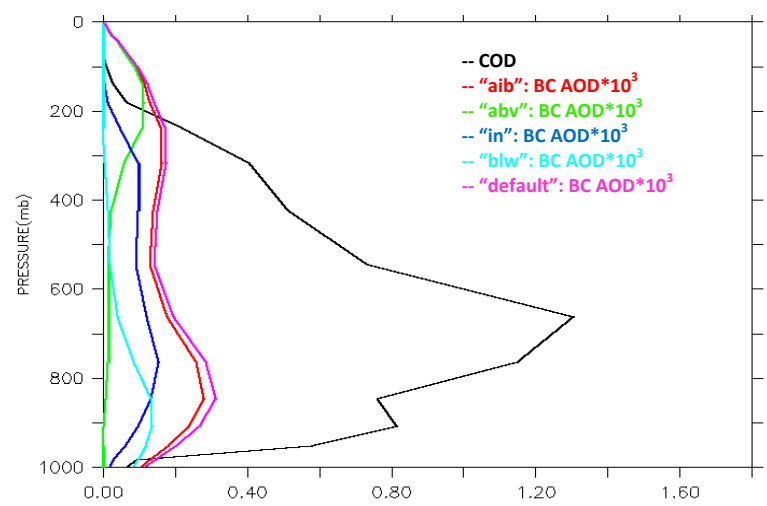

SPRINTARS

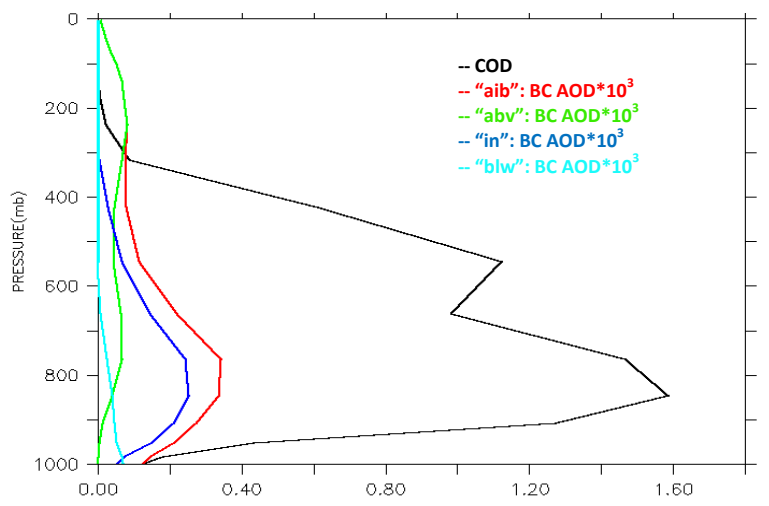

Fig. 6. Vertical profiles of $B C$ and cloud optical depths (BC AOD and COD), for reading LMDz (left) and reading SPRINTARS (right) configurations, and AIB, ABV, IN , BLW experiments. In the left panel, for comparison, we also plot the vertical profile of BC AOD for the default 3-D distribution experiment (aerosols also in completely clear columns).
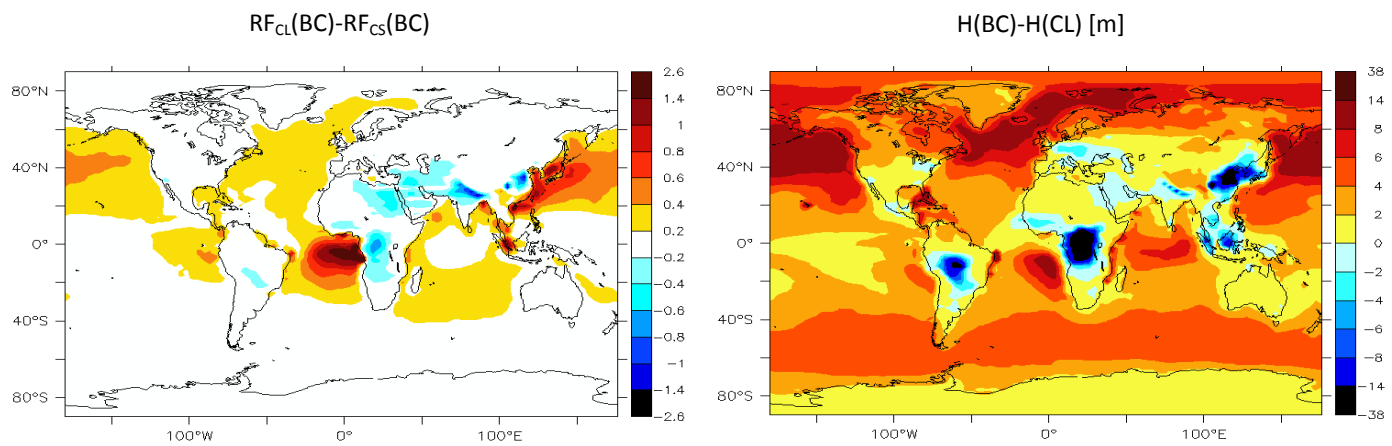

Fig. 7. Left panel: difference between cloudy- and clear-sky $B C$ forcing $\left(\mathrm{RF}_{\mathrm{CL}}(\mathrm{BC})\left[\mathrm{W} \mathrm{m}^{-2}\right], \mathrm{RF}_{\mathrm{CS}}(\mathrm{BC})\left[\mathrm{W} \mathrm{m}^{-2}\right]\right)$ for the $\mathrm{AIB}$ experiment. Right panel: characteristic height (see text for definition) of BC optical depth $(H(\mathrm{BC})[\mathrm{m}])$ minus characteristic height of cloud optical depth $(H(\mathrm{CL})[\mathrm{m}])$. The differences in heights are multiplied by the monthly product of the 2-D BC optical depth and the 2-D cloud fraction.

forcing with respect to the clear-sky value. When aerosols are below clouds, the effect that prevails is the "cloud mask": aerosols intercept less incoming radiation, thus reducing the magnitude of the forcing, regardless of sign.

With the results of Sect. 4, we showed how clouds enhance or attenuate $\mathrm{BC}$ forcing when $\mathrm{BC}$ is found above or below them, respectively. The portion of the $\mathrm{BC}$ total optical depth that is found above clouds (see Table 4) is about $30 \%$, but it is responsible of about $55 \%$ of the cloudy-sky forcing: the contribution of $\mathrm{BC}$ above clouds to the forcing is almost twice its contribution to the total optical depth. This has to be taken into account in comparisons amongst different models: a given increment of the ratio $\mathrm{AOD}_{\mathrm{BC}}(\mathrm{ABV}) / \mathrm{AOD}_{\mathrm{BC}}(\mathrm{AIB})$ means approximatively twice that increment for the cloudysky forcing from BC above clouds. This factor is slightly lower than the one found by Zarzycki and Bond (2010) for low clouds, where BC above clouds accounts for about $20 \%$ of the global burden and for $50 \%$ of the forcing.

Using a single-column model, Zarzycki and Bond (2010) also studied the sensitivity of $\mathrm{BC}$ forcing to its position rel- ative to clouds (above or below). Important differences between the two studies are that we split the $\mathrm{BC}$ vertical profile into three parts instead of "moving" the same aerosol burden from below to above clouds, and thus the "BC below/above clouds" of the two studies does not have the exact same meaning. Moreover, we do not separate forcing computations on the basis of cloud type, as is done in Zarzycki and Bond (2010). As concerns the forcing efficiency, if we scale our $\mathrm{NRF}_{\mathrm{CL}}\left(\mathrm{RF}_{\mathrm{CL}}\right.$ per unit optical depth) by the BC optical depth divided by the burden, we obtain a forcing efficiency in terms of forcing per unit mass of BC. Our cloudy-sky forcing efficiency results to be $412 \mathrm{~W} \mathrm{~g}^{-1}$ when $\mathrm{BC}$ is below clouds and $3120 \mathrm{~W} \mathrm{~g}^{-1}$ when $\mathrm{BC}$ is above clouds. These values are comparable to the ones found in Zarzycki and Bond (2010) for low, medium and high clouds. Furthermore, the enhancement factor of the forcing efficiency when passing from below to above clouds is $\mathrm{NRF}_{\mathrm{CL}}(\mathrm{ABV}) / \mathrm{NRF}_{\mathrm{CL}}(\mathrm{BLW})=7.5$ in our case (44 to $333 \mathrm{~W} \mathrm{~m}^{-2}$ per unit optical depth), of the same order of magnitude of the enhancement factor found in Zarzicky and Bond (2010) for low, medium and high clouds, 

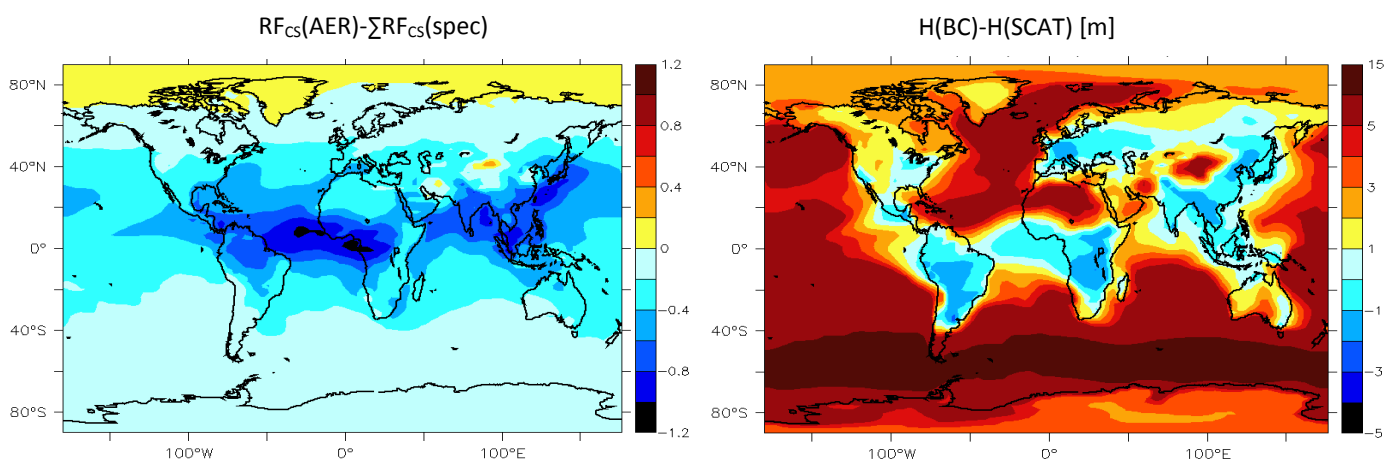

Fig. 8. Left: difference between the actual total aerosol forcing, $\mathrm{RF}_{\mathrm{CS}}(\mathrm{AER})\left[\mathrm{W} \mathrm{m}{ }^{-2}\right]$, and the sum of forcings per species, $\sum \mathrm{RF} \mathrm{CS}_{\mathrm{S}}(\mathrm{spec})$ [W m ${ }^{-2}$ ]. Right: characteristic height of BC AOD, $H(B C)[\mathrm{m}]$, minus characteristic height of the ensemble AOD of the other species, $H(\mathrm{SCAT})[\mathrm{m}]$. The differences in heights are multiplied by the product of the 2-D optical depth of BC and of the ensemble AOD of the other species.

which ranges from 5 to 13 . The enhancement factor for deep convective clouds, which cover only $2.6 \%$ of the sky in Zarzycki and Bond (2010), is much higher (240); however, in our model the deep convection scheme was not activated. This enhancement factor of forcing efficiency is important in the sense that it gives the information about how much an error in the vertical distribution of BC optical depth propagates to the forcing. With an enhancement factor of 7.5, an equal amount of BC optical depth below and above clouds would give rise to a forcing of $\mathrm{BC}$ above clouds 7.5 times larger than the forcing from $\mathrm{BC}$ below clouds, while if the ratio of the optical depths were exactly $1: 7.5$, the forcing from $\mathrm{BC}$ below and above clouds would be the same.

In order to explore the role of the vertical position of clouds for BC forcing at the regional scale, we now look at the increment in $\mathrm{BC}$ forcing when passing from clear sky to cloudy sky, $d R F=R F_{C L}(B C)-R_{C S}(B C)$. In Fig. 7, we report the horizontal distribution of yearly averaged $\mathrm{dRF}$ as well as the relative altitude of $\mathrm{BC}$ with respect to clouds, computed for each month $j$ as

$$
\begin{aligned}
(H(\mathrm{BC}) & -H(\mathrm{CL}))_{j}=\left[\frac{\sum_{i} \mathrm{AOD}_{\mathrm{BC}}\left(z_{i}\right) \cdot\left(z_{i}\right)}{\sum_{i} \mathrm{AOD}_{\mathrm{BC}}\left(z_{i}\right)}\right. \\
& \left.-\frac{\sum_{i} \mathrm{COD}\left(z_{i}\right) \cdot\left(z_{i}\right)}{\sum_{i} \operatorname{COD}\left(z_{i}\right)}\right]_{j} \cdot\left(\mathrm{AOD}_{\mathrm{BC}} \cdot \mathrm{CLT}\right)_{j},
\end{aligned}
$$

where COD is the cloud optical depth and $z_{i}$ the height from the ground to the $i$ th model level. We multiply by the monthly values of the product of $\mathrm{BC}$ optical depth and cloud fraction as a measure of the coexistence of $\mathrm{BC}$ and clouds in the same atmospheric column. This weighting does not change the sign of the difference in characteristic heights. We see from Fig. 7 that the differences of cloudy- minus clear-sky forcings (Fig. 7 - left) usually correspond to regions where the position of $\mathrm{BC}$ is below cloud (Fig. 7 right). These regions are generally land regions and also mainly emission regions for BC (central Africa, northern India, eastern Asia and South America). However, the regions where clouds enhance $\mathrm{BC}$ forcing and make it very positive $(\mathrm{dRF}>0)$ are mainly over the ocean downwind from source regions (especially western Africa and eastern Asia). In these regions BC is mainly at an altitude higher than clouds. This correspondence validates our simple approximation (Eq. A6) that predicts that the dominant term of the nonlinearity dRF is opposite to the forcing of the underlying species; that is, the nonlinearity arising when $\mathrm{BC}$ is above clouds is mainly due to the change in the underlying albedo, due to the presence of clouds, when computing the forcing of the overlying BC.

This encourages further exploration of the correlation of $\mathrm{BC}$ forcing enhancement or attenuation with the relative altitude of BC with respect to clouds (Eq. 3), the goal of this being the development of a predictive model of the $\mathrm{dRF}$ in terms of the relative altitude of $\mathrm{BC}$ with respect to clouds and cloud characteristics.

\subsection{Nonlinear combination of species forcing to total aerosol forcing}

In this section we discuss the TOA forcing effect of the presence, in the same atmospheric column, of layers of different aerosol species, neglecting the effect of clouds. In general, the total aerosol forcing $\mathrm{RF}_{\mathrm{CS}}$ (AER) differs from the sum of the forcings from individual species, as already pointed out in other studies (e.g. Boucher and Haywood, 2001; Reddy et al., 2005). We analyse the behaviour of the total clear-sky aerosol forcing and the forcings per species, in connection with the aerosol vertical distribution, for the default configuration and AIB experiment. Consider the difference between the forcing of all aerosol components AER and the sum of the individual forcings:

$$
\begin{aligned}
\mathrm{dRF} & =R F_{C S}(\mathrm{AER})-\sum \mathrm{RF}_{\mathrm{CS}}(\mathrm{spec}) \\
& =\mathrm{RF}_{\mathrm{CS}}(\mathrm{AER})-\mathrm{RF}_{\mathrm{CS}}(\mathrm{BC})-\mathrm{RF}_{\mathrm{CS}}\left(\mathrm{SO}_{4}\right) \\
& -\mathrm{RF}_{\mathrm{CS}}(\mathrm{POM})-\mathrm{RF}_{\mathrm{CS}}(\mathrm{DUST})-\mathrm{RF}_{\mathrm{CS}}(\mathrm{SS}) .
\end{aligned}
$$


The horizontal distribution of this difference, or nonlinearity, is shown in Fig. 8 (left). As a global average, dRF amounts to about $14 \%$ (see Table 2, AER and SUM columns for $\mathrm{RF}_{\mathrm{CS}}$ ), but it can reach values of $100 \%$ regionally (compare Fig. 8 left to Fig. 2 top left). The difference is due to the superposition of several aerosol layers, and not due to an internally mixed aerosol, as the approach taken in these simulations is to treat the aerosol as an external mixture. Note that the computation of RF of each species is done independently of that of the others by double calls to the radiation code. The total aerosol AER RF is computed with the fluxes that account for the volume-weighted single-scattering albedo and asymmetry factor, for each model layer. Also, the hygroscopic growth computations for the total aerosol is linear with respect to the individual components (see Sect. 3.1), meaning that the aerosol optical depth of the ensemble aerosol is simply the sum of the optical depths of the components after the hygroscopic growth has been taken into account in the computation of the individual optical depths. Thus, hygroscopic growth does not affect the nonlinearity of forcing.

In analogy to Fig. 7, Fig. 8 shows the horizontal distribution of the nonlinearity term dRF opposite the difference of the characteristic height of $\mathrm{BC}$ optical depth and that of the AOD sum of the other species $\left(\mathrm{SCAT}=\mathrm{SO}_{4}+\mathrm{POM}+\mathrm{DUST}+\mathrm{SS}\right)$. The latter are assembled as they all have a prevailing scattering behaviour and negative forcings. We are testing the hypothesis that the main contribution to the nonlinearity is the effect of the vertical superposition of components with different optical properties (i.e. with prevailing scattering or absorption).

The monthly height differences are multiplied by the product of the vertically integrated $A O D_{B C}$ and $A_{O O D} D_{S C A T}$ to give more importance to the regions where significant amounts of $\mathrm{BC}$ and the other species are found in the same atmospheric columns. Similar to the analysis in Sect. 5.1, the regions with negative (positive) dRF usually correspond to regions where BC is lower (higher) in the atmosphere than the scattering aerosols associated with other species. This corroborates the hypothesis that in the vertical superposition of different aerosol species, analogously to what happens with the ensemble "aerosols and clouds", the factor that determines the sign of the nonlinearity is which component (scattering or absorbing) is below and which one is above. Our test implies that, for values of optical depths that comparable to ours per species, the error on the forcing due only to lacking vertical superposition can be as high as $100 \%$. This corresponds to a situation where all the aerosols are horizontally juxtaposed instead of vertically superposed.

\section{Conclusions}

This study allowed for evaluating the importance of the vertical distribution of aerosols and clouds in the estimation of aerosol radiative TOA forcing with a general circulation model. We have developed a method to study and quantify the contribution of different parts of the atmospheric column to the aerosol radiative forcing in the presence of clouds. We contrast the contribution from the different components of the aerosols from below, inside and above clouds to that forcing. Two different three-dimensional fields of aerosols and clouds - coming from the LMDz and SPRINTARS model, respectively - were used to investigate the potential impact of vertical distribution on inter-model forcing differences. We used a general circulation model with a radiation module for the aerosols to simultaneously study the physical mechanisms of the interaction of light with several superposed layers, and their importance on the global scale.

This study illustrates the importance of the nonlinearity that arises from the vertical superposition of different atmospheric components by quantifying the difference between the total TOA forcing and the sum of the forcings, and the dependency of a single-component forcing on the presence and vertical distribution of the others. We investigated this phenomenon for the superposition of both aerosols (primarily BC) and clouds, as well as of different aerosol species together or computed separately. We have shown that nonlinear effects when superposing several aerosol species are not negligible, especially when considered regionally: the total aerosol forcing, computed assuming that the individual forcings sum up linearly, can differ from the actual value up to $100 \%$, and the difference amounts to $14 \%$ as a global average. A simple approximation to zero order in the transmittances of the atmospheric components allows for predicting the sign of this nonlinearity according to which species is lower in the atmospheric column. The nonlinearity is partly explained by the respective position of $\mathrm{BC}$ and the scattering part of the aerosol. In turn this means that $\mathrm{BC}$ forcing should not be computed alone. $\mathrm{BC}$ forcing might be considerably overestimated in case of scattering aerosols being overestimated below the BC-rich layers.

These nonlinear effects are even more important when superposing aerosols (in particular absorbing aerosols) and clouds. For example, the BC cloudy-sky forcing differs from its clear-sky counterpart by $+52 \%$ as a global average. The experiments performed by splitting the realistic aerosol distribution in three parts (above, within and below clouds) allowed for this increment to be attributed to the different regions of the atmospheric column, simultaneously quantifying the global-scale effect. In this way, the differences between cloudy- and clear-sky BC forcings amount to +163 , +64 and $-47 \%$ of their clear-sky counterparts when BC is found above, within and below clouds, respectively. These results reflect a strong enhancement of the forcing for $\mathrm{BC}$ above clouds, attenuation for $\mathrm{BC}$ below clouds, and a moderate enhancement when $\mathrm{BC}$ is found within clouds. Accordingly, BC forcing efficiency amounts to $44,171,333$ and $178 \mathrm{~W} \mathrm{~m}^{-2}$ per unit optical depth for BC below, within and above clouds and for the 3-D BC distribution, respectively. The overall contribution from BC within clouds (as defined 
in our model setup) is as important as that of $\mathrm{BC}$ above clouds.

Differences between aerosol forcings from different models can have several causes (e.g. different radiation computations, surface albedo, meteorology, etc.). In particular, the different behaviour of forcing nonlinearities for the regions above, within and below clouds, documented by our experiments, suggests that an important reason for differences between cloudy-sky aerosol forcings may ultimately come from different treatments of wet scavenging. Here we propose a method to investigate model differences and to isolate the effect of aerosol and cloud radiative interactions only by running one model in five different configurations. First, we run our model LMDz in the default configuration. We then read the aerosol and cloud fields in output from LMDz itself and from the model SPRINTARS into our model and subsequently compare results. The differences can be attributed to clouds and aerosols fields of the two models because the "host model" is the same and we ruled out any feedback of read aerosols and clouds fields on meteorology. The differences between cloudy-sky forcings as a global average are quite small, but can exceed $100 \%$ of the "LMDz values" regionally. These differences for cloudy skies show a regional pattern that can be interpreted with the aid of the split of the full BC distribution into three components. Indeed, in the regions where SPRINTARS exceeds the LMDz cloudysky forcing, BC optical depth above and inside clouds is also higher in SPRINTARS. To validate our results, we perform two "crossed experiments" by reading aerosols from one model and clouds from the other. The method of splitting aerosol distribution into the three components "above", "inside" and "below" clouds helps in the interpretation of the differences among the runs. The greater cloudy-sky forcing efficiencies are observed for the two configurations reading SPRINTARS and reading LMDz aerosols - SPRINTARS clouds, with values of 190 and $227 \mathrm{~W} \mathrm{~m}^{-2}$ per unit optical depth. These configurations correspond to the maximum fraction of BC above and within clouds: 85 and $88 \%$, respectively, compared to 66 and $69 \%$ for the two other configurations. Our analysis shows that the different amount of black carbon above and within clouds in the two models is the main reason for the difference in the cloudy-sky forcing efficiency, while in the range of clouds parameters considered here, the different cloud characteristics play a minor role. Myhre et al. (2013) have reported large differences between the two models, i.e. an all-sky forcing efficiency per unit optical depth of BC of $122 \mathrm{~W} \mathrm{~m}^{-2}$ (LMDz-INCA) and $171 \mathrm{~W} \mathrm{~m}^{-2}$ (SPRINTARS) from fossil and biofuel. Here we find corresponding values for all-sky forcing efficiency of total black carbon of approximately $151 \mathrm{~W} \mathrm{~m}^{-2}$ for both the LMDz and SPRINTARS configurations using the same host model. Although the BC fields used here are not exactly comparable to the ones used in Myhre et al. (2013), it is very likely that the larger differences in all-sky forcing efficiency in the original models are also caused by host model charac- teristics and not only by differences in vertical superposition of aerosol and clouds.

We have not yet characterized the nonlinear coupling terms for aerosol forcing, nor have we for pre-industrial and anthropogenic aerosols. It is difficult to predict even the sign of such coupling because it depends on covariations of aerosol species and clouds as well as their respective vertical position. However, we suggest that total aerosol forcing should be systematically compared to the sum of the forcing from its components in order to better understand any nonlinearities.

\section{Appendix A}

\section{Derivation of sign of total forcing minus the sum of individual forcings}

Consider two generic absorbing/scattering short-lived atmospheric components (they can be two different aerosol layers or an aerosol and a cloud layer) " $B$ " and " $C$ "; we use " $A$ " to refer to the clear-sky atmosphere. We are interested in the difference between the forcing when $B$ and $C$ are superposed and when they are juxtaposed. In a plane-parallel atmosphere approximation, the forcings can be expressed in terms of the bulk transmittance, reflectance and absorbance of the components (Chylek and Wong, 1998), and the fluxes computed by the "adding-doubling" method (e.g. Liu and Weng, 2006). The upward TOA flux coming from the agent $B$ alone to the lowest order in the transmittances can be written as

$F_{+}^{B}=R_{A} F+T_{A} T_{A}^{\prime \prime} R_{B} F$,

where $F$ is the incoming solar flux; $R_{A}$ and $R_{B}$ indicate the atmosphere and the component $B$ reflectances, respectively; and $T_{A}$ and $T_{A}^{\prime \prime}$ are the transmittances of the atmosphere above $B$ for the incoming and outgoing radiation, respectively (the transmittances depend on the spectral distribution of the radiation). Figure 1 (centre) describes this situation. In Eq. (A1) we neglected the terms of order $a T_{B}^{2}$ ( $a$ is the surface albedo) as well as higher-order terms; as $a<1, T_{B}<1$, we expect these higher-order terms to be less important than the ones in Eq. (A1); nevertheless, this approximation will be quite rough for optically thin atmospheric agents (large $T_{B}$ ) and high surface albedo. Analogously, the outgoing flux in clear-sky conditions can be written as

$F_{+}^{A}=R_{A} F+t_{A} t_{A}^{\prime \prime} a F$,

(see Fig. 1, left) where $a$ is the surface albedo and $t$ and $t^{\prime \prime}$ are the transmittances in clear-sky conditions. Equation (A1) can be approximated assuming that the two-way atmospheric transmittance is a constant (Corti and Peter, 2009): $T_{A} T_{A}^{\prime \prime}=t_{A} t_{A}^{\prime \prime}=k_{A}$. This allows the expression for the forcing of the atmospheric agent $B$ to be approximated in the following way:

$\mathrm{RF}^{B}=\left(F-F_{+}^{B}\right)-\left(F-F_{+}^{A}\right) \approx k_{A} F\left(a-R_{B}\right)$. 
This expression implies that the forcing is proportional to the change in reflectivity with respect to the surface albedo, due to the presence of $B$.

In the case where the $B$ layer is found above $C$ (see Fig. 1, right), and still neglecting second-order terms in the transmittances of $B$ and $C$, we can approximate the upward flux with the expression (A1) and the total forcing with the expression (A3); that is,

$$
\begin{aligned}
F_{+, \mathrm{s}}^{B+C} & \approx R_{A} F+T_{A} T_{A}^{\prime \prime} R_{B} F \\
\mathrm{RF}_{\mathrm{s}}^{B+C} & =\left(F-F_{+, \mathrm{s}}^{B+C}\right)-\left(F-F_{+}^{A}\right) \approx \mathrm{RF}^{B},
\end{aligned}
$$

where the subscript "s" denotes that $B$ and $C$ are superposed. As shown in Fig. 1 (right), in this way we neglect the terms of order $R_{C} T_{B}^{2}\left(R_{C}\right.$ is the reflectance of the underlying component $C$ ) and higher-order terms (analogously with the approximation of Eq. (A1) with respect to terms of order $a T_{B}^{2}$ and higher). Thus, this approximation will be rough for optically thin atmospheric components superposed to highreflectance ones.

If we define the nonlinearity (or coupling term) as in Sect. 2,

$\mathrm{dRF}=\mathrm{RF}^{B+C}-\mathrm{RF}^{B}-\mathrm{RF}^{C}$,

we get, in the case where $B$ is above $C$,

$\mathrm{dRF}=\mathrm{RF}_{\mathrm{s}}{ }^{B+C}-\mathrm{RF}^{B}-\mathrm{RF}^{C} \approx-\mathrm{RF}^{C} ;$

that is, the main contribution to the nonlinearity is the opposite of the forcing of the underlying species ( $C$ in this case). Like Eq. (A4), this approximation will be quite rough if $B$ is optically thin and $C$ highly reflective. Here, however, we are only interested in the dominant behaviour and investigating how useful the approximation (Eq. A6) is in interpreting the results of a GCM.

If the species $B$ and $C$ are aerosols and clouds without dynamical-microphysical interactions, the difference described by Eq. (A6) corresponds to the difference between cloudy-sky and clear-sky forcings, as explained in Sect. 2. Thus, if clouds are below the aerosol $B$, the approximation (Eq. A6) implies that the difference between the cloudy- and the clear-sky forcing will generally be positive, as it is dominated by the opposite forcing from clouds (i.e. mainly negative).

Acknowledgements. The authors would like to express their gratitude for the access granted to the HPC resources of [CCRT/TGCC/CINES/IDRIS] under the allocation 2012t2012012201 made by GENCI (Grand Equipement National de Calcul Intensif). We would also like to thank Brigitte Koffi for fruitful discussions about clouds and aerosol vertical profiles. This study has been supported by the European Commission framework contracts EUCAARI (no. 036833-2) and ECLIPSE (no. 282688).
Edited by: D. Shindell

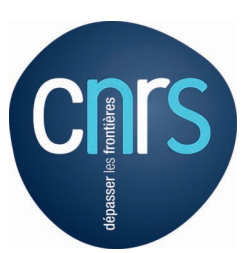

The publication of this article is financed by CNRS-INSU.

\section{References}

Albrecht, B. A.: Aerosols, cloud microphysics, and fractional cloudiness, Science, 245, 1227-1230, 1989.

Bellouin, N., Boucher, O., Haywood, J., and Reddy, M. S.: Global estimate of aerosol direct radiative forcing from satellite measurements, Nature, 438, 1138-1141, 2005.

Bellouin, N., Jones, A., Haywood, J., and Christopher, S. A.: Updated estimate of aerosol direct radiative forcing from satellite observations and comparison against the Hadley Centre climate model, J. Geophys. Res., 113, D10205, doi:10.1029/2007JD009385, 2008.

Boucher, O. and Haywood, J.: On summing the components of radiative forcing of climate change, Clim. Dynam., 18, 297-302, 2001.

Boucher, O. and Pham, M.: History of sulfate aerosol radiative forcings, Geophys. Res. Lett., 29, 1308, doi:10.1029/2001GL014048, 2002.

Boucher, O., Schwartz, S., Ackerman, T., Anderson, T., Bergstrom, B., Bonnel, B., Chylek, P., Dahlback, A., Fouquart, Y., Fu, Q., Halthore, R., Haywood, J., Iversen, T., Kato, S., Kinne, S., Kirkevag, A., Knapp, K., Lacis, A., Laszlo, I., Mishchenko, M., Nemesure, S., Ramaswamy, V., Roberts, D., Russell, P., Schlesinger, M., Stephens, G., Wagener, R., Wang, M., Wong, J., and Yang, F.: Intercomparison of models representing direct shortwave radiative forcing by sulfate aerosols, J. Geophys. Res.Atmos., 103, 16979-16998, 1998.

Chand, D., Anderson, T. L., Wood, R., Charlson, R. J., Hu, Y., Liu, Z., and Vaughan, M.: Quantifying above-cloud aerosol using spaceborne lidar for improved understanding of cloudysky direct climate forcing, J. Geophys. Res., 113, D13206, doi:10.1029/2007JD009433, 2008.

Chand, D., Wood, R., Anderson, T. L., Satheesh S. K., and Charlson, R. J.: Satellite-derived direct radiative effect of aerosols dependent on cloud cover, Nat. Geosci., 2, 181-184, doi:10.1038/NGEO437, 2009.

Charlson, R. J., Schwartz, S. E., Hales, J. M., Cess, R. D., Coakley, J. A., Hansen, J. E., and Hofmann, D. J.: Climate forcing by anthropogenic aerosols, Science, 255, 423-430, 1992.

Chepfer, H., Bony, S., Winker, D., Chiriaco, M., Dufresne, J., and Sèze, G.: Use of CALIPSO lidar observations to evaluate the cloudiness simulated by a climate model, Geophys. Res. Lett., 35, L15804, doi:10.1029/2008GL034207, 2008.

Chylek, P. and Wong, J. G. D.: Cloud radiative forcing ratio - An analytical model, Tellus A, 50, 259-264, 1998.

Conant, W. C., Seinfeld, J. H., Wang, J., Carmichael, G. R., Tang, Y., Uno, I., Flatau, P. J., Markowicz, K. M., and Quinn, P. K.: A model for the radiative forcing during ACE-Asia derived from CIRPAS Twin Otter and R/V Ronal H. Brown data 
and comparison with observations, J. Geophys. Res., 108, 8661, doi:10.1029/2002JD003260, 2003.

Cooke, W. F. and Wilson, J. J. N.: A global black carbon aerosol model, J. Geophys. Res., 101, 19395-19409, 1996.

Corti, T. and Peter, T.: A simple model for cloud radiative forcing, Atmos. Chem. Phys., 9, 5751-5758, doi:10.5194/acp-9-57512009, 2009.

Fouquart, Y. and Bonnel, B.: Computations of solar heating of the Earth s atmosphere: a new parameterization, Beitr. Phys. Atmos., 53, 35-62, 1980.

Gómez-Amo, J. L., di Sarra, A., Meloni, D., Cacciani, M., and Utrillas, M. P.: Sensitivity of shortwave radiative fluxes to the vertical distribution of aerosol single scattering albedo in the presence of a desert dust layer, Atmos. Environ., 44, 2787-2791, doi:10.1016/j.atmosenv.2010.04.041, 2010.

Hansen, J., Sato, M., and Ruedy, R.: Radiative forcing and climate response, J. Geophys. Res., 102, 6831-6864, doi:10.1029/96JD03436, 1997.

Haywood, J. M. and Ramaswamy, V.: Global sensitivity studies of the direct radiative forcing due to anthropogenic sulfate and black carbon aerosols, J. Geophys. Res., 103, 6043-6058, 1998.

Haywood, J. M. and Shine, K. P.: Multi-spectral calculations of the direct radiative forcing of tropospheric sulphate and soot aerosols using a column model, Q. J. Roy. Meteor. Soc., 123, 1907-1930, 1997.

Hourdin, F., Musat, I., Bony, S., Braconnot, P., Codron, F., Dufresne, J.-L., Fairhead, L., Filiberti, M.-A., Friedlingstein, P., Grandpeix, J.-Y., Krinner, G., Levan, P., Li, Z.-X., and Lott, F.: The LMDZ4 general circulation model: climate performance and sensitivity to parametrized physics with emphasis on tropical convection, Clim. Dynam., 27, 787-813, 2006.

IPCC, Climate Change 2007: The Physical Science Basis, Contribution of Working Group I to the Fourth Assessment Report of the Intergovernmental Panel on Climate Change, edited by: Solomon, S., Qin, D., Manning, M., Chen, Z., Marquis, M., Averyt, K. B., Tignor, M., and Miller, H. L., Cambridge University Press, Cambridge, United Kingdom and New York, NY, USA, 2007.

Koffi, B., Schulz, M., Breon, F.-M., Griesfeller, J., Winker, D., Balkanski, Y., Bauer, S., Berntsen, T., Chin, M., Collins, W. D., Dentener, F., Diehl, T., Easter, R., Ghan, S., Ginoux, P., Gong, S., Horowitz, L. W., Iversen, T., Kirkevag, A., Koch, D., Krol, M., Myhre, G., Stier, P., and Takemura, T.: Application of the CALIOP layer product to evaluate the vertical distribution of aerosols estimated by global models: AeroCom phase I results, J. Geophys. Res., 117, D10201, doi:10.1029/2011JD016858, 2012.

Li, J., Hu, Y., Huang, J., Stamnes, K., Yi, Y., and Stamnes, S.: A new method for retrieval of the extinction coefficient of water clouds by using the tail of the CALIOP signal, Atmos. Chem. Phys., 11, 2903-2916, doi:10.5194/acp-11-2903-2011, 2011.

Liao, H. and Seinfeld, J. H.: Radiative forcing by mineral dust aerosols: Sensitivity to key variables, J. Geophys. Res., 103, 31637-31645, 1998.

Liu, Q. and Weng, F.: Advanced Doubling-Adding Method for Radiative Transfer in Planetary Atmospheres, J. Atmos. Sci., 63, 3459-3465, 2006.

Meloni, D., Sarra, A. D., Iotio, T. D., and Fiocco, G.: Influence of the vertical profile of Saharan dust on the visible direct radiative forcing, J. Quant. Spectrosc. Ra., 93, 497-413, 2005.
Morcrette, J. J. and Fouquart, Y.: The overlapping of cloud layers in shortwave radiation parameterizations, J. Atmos. Sci., 43, 321328, 1986.

Myhre, G., Samset, B. H., Schulz, M., Balkanski, Y., Bauer, S., Berntsen, T. K., Bian, H., Bellouin, N., Chin, M., Diehl, T., Easter, R. C., Feichter, J., Ghan, S. J., Hauglustaine, D., Iversen, T., Kinne, S., Kirkevåg, A., Lamarque, J.-F., Lin, G., Liu, X., Lund, M. T., Luo, G., Ma, X., van Noije, T., Penner, J. E., Rasch, P. J., Ruiz, A., Seland, Ø., Skeie, R. B., Stier, P., Takemura, T., Tsigaridis, K., Wang, P., Wang, Z., Xu, L., Yu, H., Yu, F., Yoon, J.-H., Zhang, K., Zhang, H., and Zhou, C.: Radiative forcing of the direct aerosol effect from AeroCom Phase II simulations, Atmos. Chem. Phys., 13, 1853-1877, doi:10.5194/acp-13-18532013, 2013.

Peters, K., Quaas, J., and Bellouin, N.: Effects of absorbing aerosols in cloudy skies: a satellite study over the Atlantic Ocean, Atmos. Chem. Phys., 11, 1393-1404, doi:10.5194/acp-11-13932011, 2011.

Podgorny, I. A. and Ramanathan, V.: A modeling study of the direct effect of aerosols over the tropical Indian Ocean, J. Geophys. Res., 106, 24097-24105, 2001.

Quaas, J., Boucher, O., and Breon, F. M.: Aerosol indirect effects in POLDER satellite data and the Laboratoire de Meteorologie Dynamique-Zoom (LMDZ) general circulation model, J. Geophys. Res., 109, D08205, doi:10.1029/2003JD004317, 2004.

Rayner, N. A., Parker, D. E., Horton, E. B., Folland, C. K., Alexander, L. V., Rowell, D. P., Kent, E. C., and Kaplan, A.: Global analyses of sea surface temperature, sea ice, and night marine air temperature since the late nineteenth century, J. Geophys. Res., 108, 4407, doi:10.1029/2002JD002670, 2003.

Reddy, M. S., Boucher, O., Balkanski, Y., and Schulz, M.: Aerosol optical depths and direct radiative perturbations by species and source type, Geophys. Res. Lett., 32, L12803, doi:10.1029/2004GL021743, 2005.

Samset, B. H. and Myhre, G.: Vertical dependence of black carbon, sulphate and biomass burning aerosol radiative forcing, Geophys. Res. Lett., 38, L24802, doi:10.1029/2011g1049697, 2011.

Samset, B. H., Myhre, G., Schulz, M., Balkanski, Y., Bauer, S., Berntsen, T. K., Bian, H., Bellouin, N., Diehl, T., Easter, R. C., Ghan, S. J., Iversen, T., Kinne, S., Kirkevåg, A., Lamarque, J.F., Lin, G., Liu, X., Penner, J. E., Seland, Ø., Skeie, R. B., Stier, P., Takemura, T., Tsigaridis, K., and Zhang, K.: Black carbon vertical profiles strongly affect its radiative forcing uncertainty, Atmos. Chem. Phys., 13, 2423-2434, doi:10.5194/acp-13-24232013, 2013.

Satheesh, S. K., Ramanathan, V., Jones, X., Lobert, J. M., Podgorny, I. H., Prospero, J. M., Holben, B. N., and Loeb, N. G.: A model for the natural and anthropogenic aerosols over the tropical Indian Ocean derived from Indian Ocean Experiment data, J. Geophys. Res., 104, 27421-27440, 1999.

Schulz, M., Textor, C., Kinne, S., Balkanski, Y., Bauer, S., Berntsen, T., Berglen, T., Boucher, O., Dentener, F., Guibert, S., Isaksen, I. S. A., Iversen, T., Koch, D., Kirkevåg, A., Liu, X., Montanaro, V., Myhre, G., Penner, J. E., Pitari, G., Reddy, S., Seland, $\varnothing$., Stier, P., and Takemura, T.: Radiative forcing by aerosols as derived from the AeroCom present-day and pre-industrial simulations, Atmos. Chem. Phys., 6, 5225-5246, doi:10.5194/acp-65225-2006, 2006. 
Simmons, A., Uppala, S., Dee, D., and Kobayashi, S.: ERA-Interim: new ECMWF reanalysis products from 1989 onwards, ECMWF Newsletter articles, 110, 25-35, 2006.

Takemura, T., Nakajima, T., Dubovik,O., Holben, B. N., and Kinne, S.: Single scattering albedo and radiative forcing of various aerosol species with a global three-dimensional model, J. Climate, 15, 333-352, 2002.

Takemura, T., Nozawa, T., Emori, S., Nakajima, T., and Nakajima, T.: Simulation of climate response to aerosol direct and indirect effects with aerosol transport-radiation model, J. Geophys. Res., 110, D02202, doi:10.1029/2004JD005029, 2005.

Turpin, B. J. and Lim, H. J.: Species contributions to $\mathrm{PM}_{2.5}$ mass concentrations: Revisiting common assumptions for estimating organic mass, Aerosol Sci. Tech., 35, 602-610, 2001.

Twomey, S.: Pollution and the planetary albedo, Atmos. Environ., $8,1251-1256,1974$
Twomey, S.: Aerosols, clouds, and radiation, Atmos. Environ., 25, 2435-2442, 1991.

Visser, H., Folkert, R. J. M., Hoekstra, J., and de Wolff, J. J.: Identifying Key Sources of Uncertainty in Climate Change Projections, Clim. Change, 45, 421-457, 2000.

Vuolo, M. R., Chepfer, H., Menut, L., and Cesana, G.: Comparison of mineral dust layers vertical structures modelled with ChimereDust and observed with the Caliop lidar, J. Geophys. Res., 114, 1984-2012, doi:10.1029/2008JD011219, 2009.

Zarzycki, C. M. and Bond, T. C.: How much can the vertical distribution of black carbon affect its global direct radiative forcing?, Geophys. Res. Lett., 37, L20807, doi:10.1029/2010g1044555, 2010 . 